\title{
COMPOSITION, PURIFICATION, AND CERTAIN CONSTANTS OF AMMONIA.
}

\author{
By E. C. McKelvy and C. S. Taylor. ${ }^{a}$
}

ABSTRACT.

Chemical tests made on several standard brands of commercial ammonia indicate that most commercial brands contain less than o.I per cent of impurities. Fifteen samples of purified ammonia were prepared by five different methods for use in the determination of the various thermodynamical properties of ammonia. These samples were found to contain less than o.or per cent, by weight, of water; from approximately I part in Io,000 to I part in I,,00,000, by volume, of noncondensing gases; and less than 0.001 per cent of other impurities. Determinations were made of the density of the solid, freezing point, and vapor pressure at the triple point.

\section{CONTENTS.}

Page.

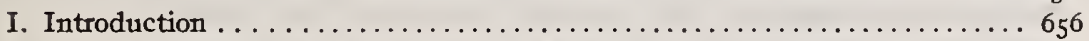

II. Work on the composition and testing of commercial liquid ammonia. . . . 656

I. Purpose and previous work . . . . . . . . . . . . . . . . . . . . $65^{6}$

2. Nature of impurities in ammonia. . . . . . . . . . . . . . . 657

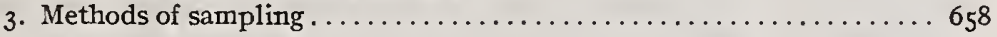

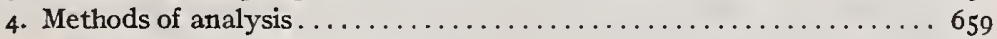

(a) Noncondensing gas. . . . . . . . . . . . . . . . . . 659

(b) Residue on evaporation . . . . . . . . . . . . . . . 66

(c) Volatile materials containing carbon..............6663

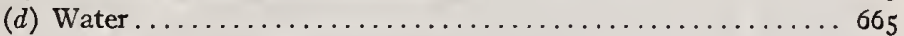

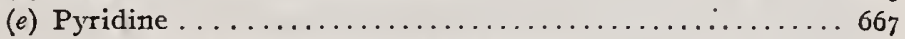

(f) Acetonitrile and ammonium acetate. . . . . . . . . . 668

(g) Direct determination of ammonia. . . . . . . . . . . . 669

5. Experimental results. . . . . . . . . . . . . . . . . . . . . . . . 669

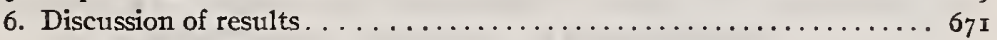

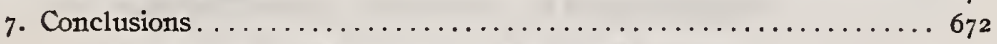

(a) Composition of commercial ammonias............6 672

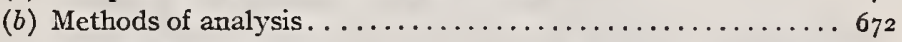

(c) Standards of quality ......................... 672

III. Preparation of pure ammonia for the determination of its thermodynamical

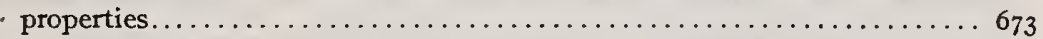

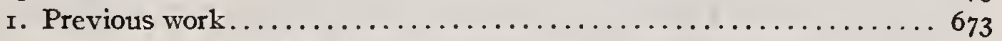

2. Description of apparatus. . . . . . . . . . . . . . . . . . 676

(a) Vacuum fractional distillation apparatus.............6. 676

(b) High-pressure fractional distillation apparatus. . . . . . . 677

3. Methods of preparation of samples. . . . . . . . . . . . . . 678

a This investigation was being carried on at the time of the death, in November, 1919, of the senior author. The manuscript was prepared subsequently by the junior author, with the assistance and cooperation of C. S. Cragoe. 
III. Preparation of pure ammonia for the determination of its thermodynamical properties-Continued.

4. Tests for noncondensing gases......

(a) Application of

in

(b) Liberation of gases in sealing off glass apparatus.........6 684

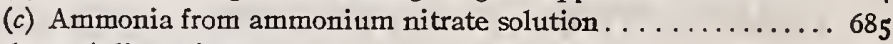

5. Results and discussion ........................... 686

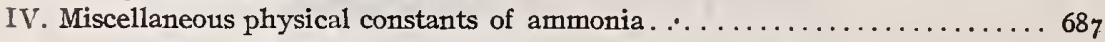

I. Density of solid ................................. $68_{7}$

2. Temperature at the triple point and elevation of freezing point with pressure .....................................6. $68_{9}$

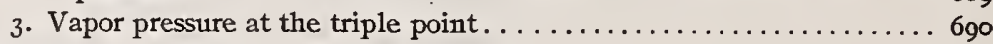

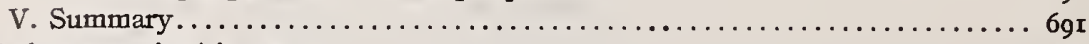

References cited in paper................................

\section{INTRODUCTION.}

The work presented in this paper forms a portion of that undertaken by the Bureau of Standards on the determination of the physical constants of materials used as refrigerating media. Several of these constants for ammonia have already been determined and published in separate papers, ${ }^{b}$ namely, specific heat of the liquid, ${ }^{1}$ latent heat of pressure variation, ${ }^{2}$ latent heat of vaporization, ${ }^{3}$ vapor pressure, ${ }^{4}$ and specific volume of the liquid. ${ }^{5}$

The most refined physical measurement would have no real value unless assurance was given that the materials used were of very high purity. The present paper describes in detail the methods of purification and the tests for purity of the samples used in the above investigation and in others to be published later.

In order to ascertain the best sources of ammonia with which to start the preparation of the pure material, an investigation was undertaken of the commercial samples of liquid ammonia obtained in the open market.

\section{WORK ON THE COMPOSITION AND TESTING OF COMMERCIAL LIQUID AMMONIA. ${ }^{c}$}

\section{PURPOSE AND PREVIOUS WORK.}

The object of this work was not only (I) to find a material among the various commercial brands which could best serve as a starting point for further purification on a small scale in the laboratory, but also (2) to determine the general quality of the materials on the market by means of tests already existing or others that might be devised, and (3) to acquire information that would afford some

\footnotetext{
$b$ Superior numbers refer to bibliography references at the end of the paper.

c The results of this work were communicated to and published by the American Society of Refrigerating Engineers in $1917 .^{\circ}$
} 
idea of the proper standards of purity for liquefied ammonia for use in the industries and in the laboratory.

Although various impurities have been reported in commercial ammonia and considerable work has been done upon the methods of analysis, few exhaustive examinations have been made, especially upon the comparative purity of different samples. In 1892 $\mathrm{H}$. von Strombeck ${ }^{7}$ examined II American samples made by different processes or from different materials, but did not publish the details of his methods. In r898 A. Lange and W. Heffter ${ }^{8}$ examined the residues left by evaporation of four German samples. In I 9ro W. D. Richardson ${ }^{9}$ reported results upon the content of noncondensing gas and the residue left on the evaporation of five American products. Even in extended scientific investigations upon reactions and equilibria in liquid ammonia few chemical analyses or physical tests of the purity of either the starting or the final material have been reported, so that adequate proof of the purity is generally lacking. A. W. Browne and A. E. Houlehan ${ }^{10}$ made certain chemical tests upon the ammonia used by them in their investigations.

\section{NATURE OF IMPURITIES IN AMMONIA.}

In $1892 \mathrm{H}$. von Strombeck ${ }^{7}$ found the following impurities to be present in American liquefied ammonia, without, however, furnishing conclusive identification in every case, namely, water, methyl, ethyl, and isopropyl alcohols, acetone, and carbon dioxide (present as ammonium carbonate). In addition, there were found mineral oil, sand, iron oxide, and iron sulphide, which may be regarded as accidental impurities introduced during liquefaction or from the iron containers. In I897 A. Lange and J. Hertz ${ }^{11}$ identified with considerable certainty the following impurities, namely, water, pyridine and some of its homologs, nicotine, ethyl alcohol, acetonitrile, ammonium carbonate, and mineral oil. Benzene and naphthalene were found occasionally. They were unable to detect the presence of acetone or of any alcohols other than ethyl alcohol. The presence of noncondensing gas in the container was also noted. The noncondensing gas present in American samples has been found recently by W. D. Richardson ${ }^{2}$ to consist of a mixture of oxygen and nitrogen approaching the composition of air, with in some cases a small amount of hydrogen. $\mathrm{K}$. Urban ${ }^{12}$ suggested the occurrence of pyrrol in ammonia, without, however, presenting any proof of its presence. 
Although only the above impurities have been reported in liquid ammonia, there are a number of substances which, considering the source of the ammonia, might conceivably be present, though they have never been detected. They are, in general, of such a nature that they would volatilize when ammonia is evaporated and would therefore readily escape detection by the methods used by most of the early investigators. Such impurities might be (I) carbon monoxide and hydrocarbons, such as methane, ethane, and ethylene. Such substances, if present in appreciable amounts, could be detected by the analysis of the gases not absorbed by dilute sulphuric acid; (2) low boiling organic homologs of ammonia, such as methyl and ethyl amines. These would be absorbed when the gas is passed through acid solution; (3) oxidation products of ammonia, such as hydroxylamine, nitrous, and nitric acids. The former would be absorbed by passing the gas through acid, while the latter two would appear as ammonium salts in the residue from the evaporation of the ammonia. The possibility of any or all of these impurities being present must be considered in any scheme of analysis.

\section{METHODS OF SAMPLING.}

The various methods for sampling are based upon the assumption that the ammonia consists of one homogeneous liquid phase in contact with the gas phase, an assumption that is entirely justifiable, with one exception, as applied to the commercial materials examined by the authors. The additional phases when present are, in general, of such a nature as to influence slightly the composition of the liquid ammonia, though the effects which they may have upon the results of analysis depend entirely upon their amount and distribution in the container. For example, in drawing the first sample of liquid ammonia from a container it is likely that considerable lubricating oil and possibly fine particles of iron oxide will be carried out mechanically with the rush of liquid. Before taking samples of the liquid for the various tests the aim was in all cases to avoid inclusion of this material by blowing off such an amount of liquid as seemed adequate to remove all substances of the above character. In general, the liquid appeared homogeneous, though rarely were we able to obtain a sample which did not show on standing at least a few particles, negligible in amount, of inert solid material. In those methods of sampling in which a definite volume is measured out at atmospheric pressure a variable 
amount of the sample is lost, depending upon the amount of evaporation necessary to cool down the receptacle and the ammonia except where absorption methods of determining the amount of ammonia evaporated are used. In order to carry out the most accurate analyses, it is necessary that the amount of material taken be subject to exact gravimetric estimation. No difficulty was found in taking, by means of an apparatus (Fig.I) to be described later, samples of from 50 to $75 \mathrm{~g}$ of any desired ammonia and determining its weight within a milligram, an accuracy which is far above that generally required in analyses of this character.

Samples should not be taken from the gas phase, as the gas distilled off will not be a representative sample of the material in the drum. In addition the content of the nonvolatile impurities in the remaining liquid is thereby increased. It is necessary, however, to take a small sample from the gas phase in determining its content of noncondensing gas. Where the container is of large capacity any change in the remaining material can be regarded as negligible.

\section{METHODS OF ANALYSIS.}

(a) Noncondensing Gas.-The tendency of liquid ammonia to absorb the permanent gases was noted by $\mathrm{F}$. W. Frerichs, ${ }^{13}$ who suggested a method for their estimation by collecting over water in a eudiometer. W. D. Richardson ${ }^{9}$ was the first to determine the amount and nature of the gas occurring in commercial samples in both gas and liquid phases. The method consisted simply in absorbing ammonia in dilute acid solution and collecting the residual gas in a eudiometer. This method is by no means free from objection, especially if the amount of residual gas is very small. The temperature of the solution is raised considerably by the absorption of the ammonia, thus freeing the gases originally held in the acid, and the results obtained are likely to be too high. This objection can not be obviated by the simple expedient of expelling before use the gases dissolved in the acid solution. If that is done, it is possible that some of the gases of the ammonia would become dissolved in the absorbing solution, the results being in consequence too low. By using in every case an absorbing solution of the same nature and temperature and a eudiometer of the same size the results obtained are at least relatively correct. For large amounts of gas, say a few cubic centimeters per gram of ammonia, errors from the above sources become negligible. 
Richardson's method with suitable precautions was therefore used in this work, and the composition of the gas obtained was determined by the usual methods of gas analysis. Where the amounts of residual gas available were very small, the results of analysis were, of course, only approximate. In the purification of ammonia for use in determining those physical properties which may be considerably affected by the presence of noncondensing gases a more accurate method for determining their amount was devised. This method will be described in detail later in this paper.

The total volume of noncondensing gas that may occur in a given cylinder, excluding the possibility of hydrogen formation by the action of moisture upon the inside of the cylinder, is equal to the capacity of the cylinder. This maximum amount could be present only if the liquid ammonia was transferred into a cylinder filled with air at atmospheric pressure without evacuating or blowing off the gases in any way after filling in part with ammonia. In a roo-pound drum filled to 85 per cent of its capacity with liquid under the above conditions the noncondensing gas in the gas phase, assuming its uniform distribution and neglecting the small amount dissolved in the liquid, would be about $\mathrm{I}, \mathrm{IOO} \mathrm{cc}$ per gram of ammonia, corresponding to a content of noncondensing gas in the expanded mixture of 44 per cent, by volume. This amount is three times the highest observed by Richardson ${ }^{9}$ and over ten times the highest observed by us. While there is no question as to the undesirability of introducing large volumes of air into the system in this manner, it has been shown by H. Dannenbaum ${ }^{14}$ that such an air content as found in samples $A, B$, and $\mathrm{C}$ tested by Richardson ${ }^{9}$ and all the samples tested by us, with a few exceptions, was of negligible importance and influence as affecting the operation of refrigerating systems. The significance of the noncondensing gas test is rather to be found in the indication it may give as to the care used by the manufacturer in cleaning and filling his drums, and therefore at least a parallelism with the results of other tests indicating the quality which might be expected.

In connection with the sampling of ammonia to determine the content of noncondensing gas it is well to consider the conditions existing in a cylinder of liquid ammonia. Considering (for the sake of simplicity) the noncondensing gas as one component, the system consists of two components in two phases, which gives, 
according to the phase rule, a bivariant system; that is, one possessing two degrees of freedom. In other words, at fixed temperature, equilibrium conditions being assumed, the system becomes unvariant, and fixing the composition determines the pressure and vice versa. For instance, if the composition is fixed the pressure can only have one value, and the ratio of the content of noncondensing gas in the gas and liquid phases will be constant. Obviously, no sample can be drawn without disturbing equilibrium conditions, but the removal of a portion of the gas phase will have a greater effect upon the composition of both phases than would the removal of a portion of the liquid phase. This effect can be made small and practically negligible by making the sample small as compared with the amount of material in the entire system.

(b) Residue on Evaporation.--The determination of the residue left on evaporation has formed the basis of most of the investigations of commercial liquid ammonias. Work of this character has been carried out by $\mathrm{H}$. von Strombeck, ${ }^{7} \mathrm{~A}$. Lange, ${ }^{15}$ A. Lange and J. Hertz, ${ }^{11} \mathrm{H}$. Bunte and P. Eitner, ${ }^{16} \mathrm{~K}$. Urban,${ }^{12}$ A. Lange and W. Heffter, ${ }^{8}$ and R. Lucion and D. De Paepe. ${ }^{17}$ Apparatus and methods for this purpose have been devised by several of the above as well as the Linde Gesellschaft für Eismaschinen, ${ }^{8,18}$ Roller, ${ }^{19}$ Société Solvay, ${ }^{17}$ F. W. Frerichs, ${ }^{13}$ and H. Sallwasser, $\mathrm{jr} .{ }^{20}$ In addition, a considerable amount of work has been done in testing the various methods on samples of ammonia to which known amounts of impurities had been added. Work has been carried out along this line by A. Lange and W. Heffter ${ }^{8}$ and F. W. Frerichs, ${ }^{13}$ who also presents a critical review of most of the earlier work on this general subject and a description of the apparatus employed.

R. Lucion and D. De Paepe ${ }^{17}$ used a calorimetric bomb weighing $2 \mathrm{~kg}$ in order to weigh out accurately $\mathrm{I} 60$ to $\mathrm{I} 7 \mathrm{~g} \mathrm{~g}$ of liquid ammonia. In other respects they used the procedure of Bunte and Eitner. ${ }^{16} \mathrm{H}$. Sallwasser, jr., ${ }^{20}$ weighed out small quantities ( 5 to $20 \mathrm{~g}$ ) of liquid to the second decimal place without appreciable loss in small vacuum jacketed cylinders protected from the air by a rubber cap and provided with inlet tube for liquid and outlet tube for the gas, the former provided with a plug and the latter with a Bunsen valve.

In the work at this bureau evaporation tests were carried out upon samples of about $60 \mathrm{~g}$ weighed out under pressure in a cylindrical glass bulb to which metal valves were fastened either $17323^{\circ}-23-2$ 
by Khotinsky cement or by means of a glass-metal joint made as described by the present authors. ${ }^{21} \mathrm{~A}$ Khotinsky joint is satisfactory for about I 2 hours, after which it begins to soften. A glass-metal joint will hold just as perfectly as any soldered joint and has proved extremely valuable in working with liquid ammonia. Figure I illustrates the type of container employed in the laboratory. This glass bulb container after evacuation was connected to the large cylinders of ammonia by means of suit-

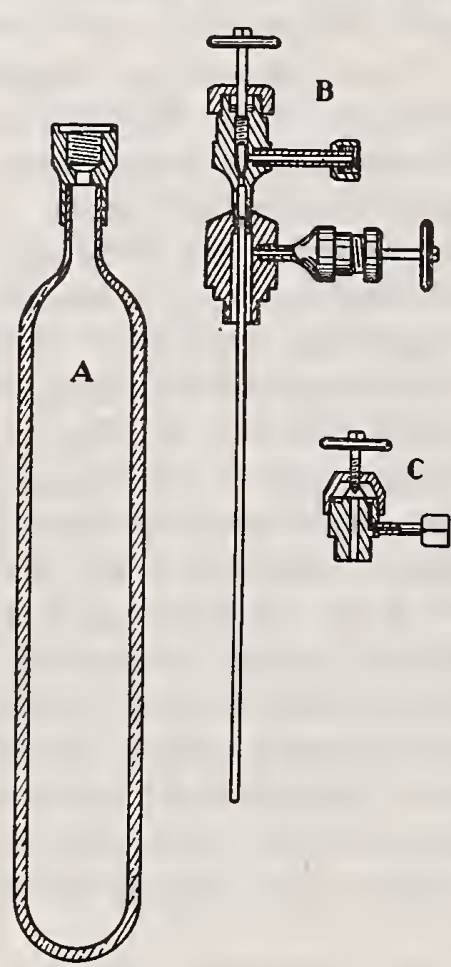

FIG. I.-Liquid ammonia container (glass bomb); $A$, glass bulb sealed to steel cap; $B$, needle valve; $C$, diaphragm valve. able flexible steel connecting tubes and the bulb practically filled each time with liquid ammonia and then carefully weighed. The samples in the bulb were then allowed to evaporate by two methods: (I) At atmospheric pressure, in which case the ammonia cooled quickly to its boiling point; and (2) at the pressure corresponding to room temperature, to maintain which heat was supplied from without. The residues obtained were weighed and inspected. Since concordant results were obtained in all cases where duplicate determinations were conducted by a given method, in general, only one determination was made by each method upon each sample. Although less residue might be expected by evaporation at the higher temperature, the results by the two methods were fairly concordant and showed no regular difference.

There is considerable difference of opinion as to the significance and importance of the evaporation test as carried out on from 50 to $75 \mathrm{~g}$ of material. Commercial ammonia has been produced which on evaporation of very large quantities yields an almost negligible residue. When considerable residue is found, the presence of foreign material is definitely proved. When the residue is very small and consists almost entirely of traces of moisture, lubricating oil, and particles of solid material, the purity of the material is not proved, since, as pointed out by F. W. Frerichs, ${ }^{13}$ 
some of the impurities present may have evaporated with the ammonia. The main value of the evaporation test is to show which ammonias have received insufficient care in purification and handling. This same information may be attained conveniently with the proper precautions by the simple flask method which is employed by many manufacturers in testing the contents of every cylinder after charging.

(c) Volatille Materials Containing Carbon.-Very little definite information is available as to the extent to which impurities pass off with the ammonia when the latter is evaporated. Some indication is given when certain definite impurities are added to the liquid and an attempt is made to recover them quantitatively in the residue. Experiments of this character have been conducted by A. Lange and W. Heffter ${ }^{8}$ and F. W. Frerichs. ${ }^{13}$ Even when under such conditions the added impurities were recovered quantitatively in the residue, there is no conclusive proof that the ammonia did not originally contain that proportion of the particular impurity which would evaporate at a given temperature from its binary mixture with ammonia. The amount of any impurity which passes off with the ammonia gas on evaporation at a given temperature depends roughly upon its normal boiling point and more exactly upon the pressure-concentration relations in the binary system under consideration. The first relation is illustrated by the fact that the gas from a mixture of liquid ammonia and ethyl ether contains so much ether that when evaporated freely at room temperature and ignited it will burn continuously. On the other hand, very little water evaporates from its mixture with liquid ammonia and still less lubricating oil. Although it is known that the boiling point is not the only criterion of the composition of the evaporating gas, the characteristics of the binary systems of interest have not been sufficiently studied, especially at low concentrations of impurity, to justify prediction of the composition of the gas phase. Little work has been done on the examination of the gas itself, and most methods heretofore applied have not been such as to yield reliable results.

In $1912 \mathrm{H}$. Sallwasser, jr., ${ }^{20}$ devised a method of analysis in which the ammonia containing carbonaceous material, both that which is volatile with the ammonia and that which is taken over by a stream of dry air free from carbon dioxide, is passed through a cooled solution of sodium nitrite and sulphuric acid. The 
ammonia is oxidized to nitrogen and water, while any amines are converted into nitrogen and their corresponding alcohols. Pyridine and benzene, not reacting with nitrous acid, will remain in the absorbing solution. To the latter chromic acid is added, whereby the organic matter is oxidized to carbon dioxide, which is determined in the usual manner. Experiments of Sallwasser with known amounts of pyridine, added to ammonia which of itself yielded no carbon dioxide by the above treatment, gave satisfactory results. Owing to the complications involved and

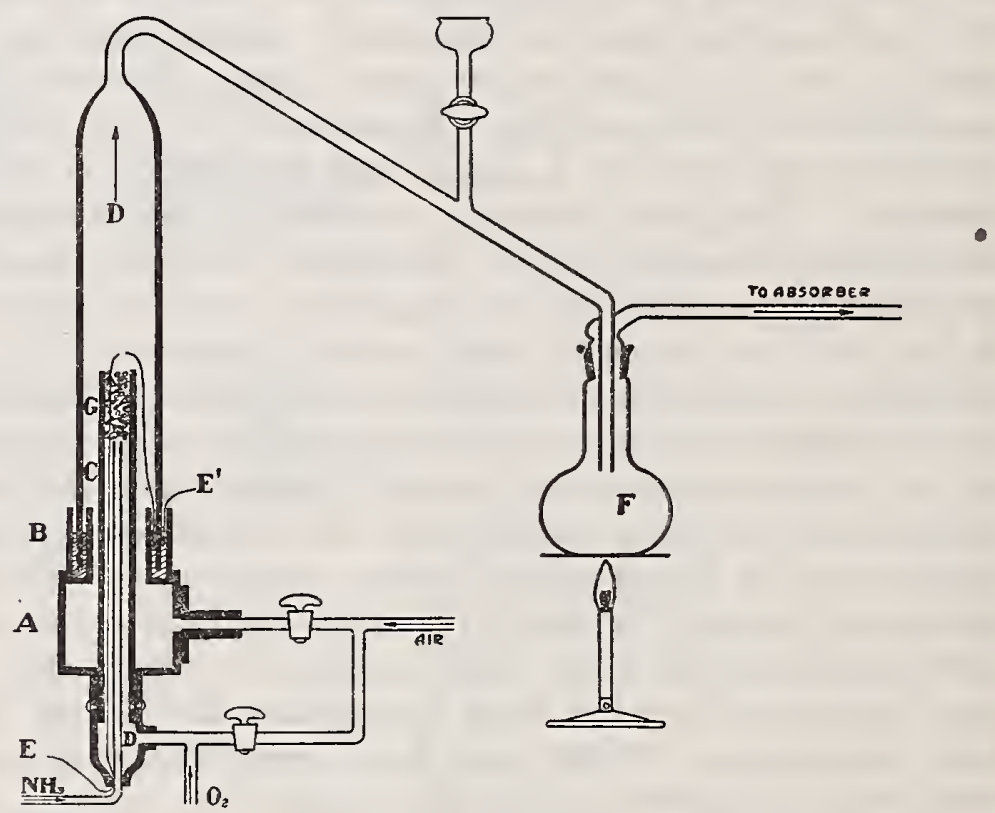

FIG. 2.-Combustion apparatus for determining volatile carbon compounds; $A$, brass air chamber; $B$, steel mercury well; $C$, porcelain tube; $D$, glass tube; $E, E^{\prime}$, ignition leads; $F$, trap; $G$, pieces of quartz.

the readily apparent objections to the above method no use was made of it in the present work.

Combustion was carried out in a modified. Drehschmidt apparatus (Fig. 2) similar to the forms devised by R. S. McBride and E. R. Weaver ${ }^{22}$ and E. R. Weaver and J. D. Edwards ${ }^{23}$ for determining the sulphur content of illuminating gas, but so modified as to meet the somewhat different demands. A weighed quantity of liquid ammonia (6o to $75 \mathrm{~g}$ ) in a special glass container (Fig. I) was evaporated and mixed with carbon free oxygen, which mixture was ignited by an electric spark and burned continuously 
in air. As a result of complete combustion the ammonia was converted into nitrogen and water, and any volatile carbonaceous material was oxidized to carbon dioxide. The latter was absorbed by means of barium hydroxide solution in a spiral wash bottle of the type devised by E. R. Weaver and J. D. Edwards. ${ }^{24}$ The resultant barium carbonate was filtered out and estimated by well-known volumetric or gravimetric methods. Owing to the large amount of water formed, a trap, as shown in Figure 2, was placed between the burner and the absorber for the purpose of condensing the water, which was finally acidified and boiled to expel all the carbon dioxide. The amount of the carbon dioxide thus formed gives a measure of the amount of volatile carbonaceous material present, but gives no evidence as to its nature. Before adopting this type of burner combustions were carried out in which all the products of combustion were recovered in order to determine whether the combustion was complete and whether all the ammonia was converted into water and nitrogen. A sample of about $50 \mathrm{~g}$ of ammonia yielded on combustion besides the requisite amount of water traces of nitrites and nitrates. The total amount calculated as nitric acid amounted to $0.05 \mathrm{~g}$. There was no ammonia or ammonium salts present.

This method was applied to the analysis of mixtures containing known amounts of various impurities with a specially prepared ammonia which gave no carbon dioxide when burned. No commercial sample of ammonia met this requirement. In general, the carbon dioxide obtained corresponded to only a portion of the added impurity, the highest percentage recovery being with comparatively small additions. For example, when $15 \mathrm{mg}$ of acetonitrile was added to $5^{8} \mathrm{~g}$ of ammonia 67 per cent of the calculated yield of carbon dioxide was obtained, while with $3 \mathrm{mg}$ of acetonitrile in the same amount of ammonia 95 per cent was obtained. The results by this method should be regarded as approximate, but are very useful for indicating the absence of hydrocarbon gases and volatile amines.

(d) WATER.-The small quantities of water which ordinarily occur in most commercial brands of ammonia and which are not shown by the evaporation tests have very little significance as regards their use for refrigeration purposes. It is important, however, to have adequate methods for determining the water in samples that are to be used for the determination of physical constants. The determination of water is, in general, a difficult 
problem, particularly in this case, owing to the many chemical properties possessed in common by water and ammonia. F. W. Frerichs ${ }^{13}$ used metallic sodium, taking advantage of the fact that sodium reacts with ammonia more slowly than with water. $\mathrm{He}$ therefore considered the hydrogen evolved during the period of rapid evolution as a measure of the water present. He found also that samples containing, according to his method, two parts of water in 100,000 of ammonia yielded an appreciable residue of water in the evaporation test.

In connection with the tests for residue on evaporation the gaseous ammonia was passed through weighed drying tubes containing solid potassium hydroxide. An idea of the relative water content can be obtained in this way only when comparatively large amounts of water are present.

The reaction between calcium carbide and water has been applied to the determination of water as a specific method. The conditions for applying this method, in general, have been worked out by $\mathrm{E}$. R. Weaver ${ }^{25}$ of this bureau, who very kindly assisted us in applying the method to the determination of water in ammonia. Calcium carbide which had been prepared according to the method described by Weaver ${ }^{25}$ was placed in a small bulb provided with inlet and outlet tubes drawn down to capillaries. The inlet tube was then sealed to valve $B$ of the liquid ammonia container (Fig. I) with Khotinsky cement and the outlet tube connected to a vacuum pump. After washing out by admitting a little ammonia to remove any acetylene that might be in the carbide the bulb was exhausted and the outlet tube sealed off by fusion of the glass capillary. The bulb was then cooled in a mixture of solid carbon dioxide and gasoline and from $\mathrm{I}$ to $3 \mathrm{~g}$ of ammonia admitted. The bulb was then sealed by fusion of the capillary of the inlet tube. Several samples of ammonia from each source were taken in this manner and allowed to stand Io days or longer with occasional shaking. The two capillary tips were then scratched with a glass knife, the inlet tube connected by small rubber tubing to a cylinder of dry hydrogen under slight pressure, which could be regulated with a valve. The outlet tube was connected in the same way to a small sulphuric acid wash bottle, which, in turn, was connected to the acetylene absorbing solution described by $\mathrm{E}$. R. Weaver. ${ }^{25}$ The bulb was then cooled down in liquid ammonia, the tips broken off by pressure through the rubber connections, 
and the acetylene driven over into the absorbing solution by a slow stream of hydrogen, the bulb being allowed to warm up to room temperature. The amount of acetylene was determined by colorimetric comparison, as described by $\mathrm{E}$. R. Weaver, ${ }^{25}$ and thus the amount of water could be calculated. A large number of determinations were carried out by this method. Triplicate determinations on the same sample gave results in excellent agreement with one another.

(e) PYRIDINE.-The amount of pyridine found in practically all the samples examined is insignificant, since pyridine is a stable substance, almost as inert as ammonia under ordinary working conditions in the compressor. When present in large amounts, pyridine is considered an objectionable impurity owing to its deleterious action on rubber gaskets.

Various methods for the determination of pyridine in and its separation from ammonia have been proposed, but none thus far suggested can be applied to the very small amounts present in the samples examined by us. According to F. W. Frerichs, ${ }^{13}$ 9 parts of pyridine in I0O,000 parts of ammonia can be detected by the evaporation test. Pyridine and some of its homologs would be included in the results of the combustion test previously described, though with what accuracy it is difficult to say.

The following method, which combines the features of several proposed methods, has been found satisfactory to detect as little as $0.00 \mathrm{I}$ per cent of pyridine; that is, I part in 100,000 , using a IOo $\mathrm{g}$ sample of the liquid ammonia. The latter is converted to nitrate or sulphate, using as little excess of acid as possible, after which the solution is evaporated until crystals begin to separate. The concentrated solution is transferred to a separatory funnel, rendered alkaline by the addition of solid sodium hydrogen carbonate (or its saturated solution), and is then shaken with ether. The sodium hydrogen carbonate has no action upon the ammonium salt, but liberates the pyridine, which dissolves in the ether and can then be removed with it. The solution is shaken two more times with ether, and the combined ether extract is treated with water and sufficient dilute nitric acid to render it slightly acid. The mixture is then evaporated to a small volume, transferred to a small distilling flask, together with a small piece of zinc (to prevent bumping), and is then rendered alkaline with sodium or potassium hydroxide. 
Two-thirds of the liquid is distilled into a small test tube containing I cc or less of a saturated solution of mercuric chloride. The distillate is heated almost to boiling and filtered into a small test tube. Upon cooling slowly a double salt of pyridine and mercuric chloride separates out in clusters of long needles, from the volume of which the pyridine content can be roughly estimated. Analyses of ammonia containing known small amounts of pyridine have yielded satisfactory results.

( $f$ ) Acetonitrile and Ammonium Acetate.-Acetonitrile is generally recognized as being an impurity difficult to remove in the manufacture of ammonia. This impurity and the possibility of its transformation into ammonium acetate are likely to be of considerable significance, especially where anhydrous ammonia is added to strengthen the charge in absorption systems. Little published evidence of this transformation in the plant exists

Ammonium acetate, or ammonium salts of other organic acids, if dissolved in the liquid ammonia will probably be left in the residue on evaporation. Acetonitrile if present will be included in the volatile carbon compounds determined by the combustion test. If the ammonia is absorbed in water and made slightly alkaline with potassium hydroxide, any acetonitrile present will dissolve and on evaporation be at least partially converted into potassium acetate. If, therefore, ammonium acetate is not found in the residue upon evaporation, but is found by the following test, or if the amount found in the latter test is appreciably in excess of that found by direct evaporation, the presence of acetonitrile in the original ammonia is indicated. The test used for detecting small quantities of ammonium acetate (and indirectly acetonitrile) is as follows: One liter of strong aqua ammonia made from the liquid phase is evaporated almost to dryness after the addition of to drops of 50 per cent potassium hydroxide solution. Hydrochloric acid is added drop by drop until the solution is just acid to phenolphthalein, after which saturated barium hydroxide solution is added until the reaction is alkaline. After filtration into a small porcelain crucible and exact neutralization with hydrochloric acid a few drops of ferric chloride solution are added. A characteristic reddish brown color is produced if any acetate is present. The method may be made semiquantitative for very small amounts by comparison with the colors produced by known amounts of acetate. By this method it was found possible to detect 0.005 per cent, an amount considerably 
smaller than could be detected by the ethyl acetate or cacodyl tests, which depend upon the sense of smell.

(g) Direct Determination of Ammonia.-Lange and Heffter ${ }^{8}$ considered that the ideal method for determining the quality of a liquid ammonia would be that in which a sample of the ammonia could be sealed up in glass, weighed, and determined directly by titration with standard acid. In making such a recommendation they overlooked the fact that the accuracy of such a titration even with special precautions is limited by the nature and suitability of the indicator, and that certain impurities such as the amines would affect the results.

In order to determine the practical effect of these limitations, a few such direct determinations were carried out by the authors. The sample of ammonia ( $\mathrm{r}$ or $2 \mathrm{~g}$ ) cooled to liquid air temperature was sealed into a small glass bulb provided with a small capillary tube so constructed that it could be readily broken off under the surface of the absorbing acid. The weight of the ammonia was obtained from the weight of the bulb before and after filling, taking account of the piece of glass removed during the sealing-in process. With the greatest precautions, using weight titrations, it was not found possible to obtain results upon the same sample that always agreed to I part in I,ooo. Obviously, therefore, such results are of little value except as a rough check upon amounts of impurities found by other methods.

\section{EXPERIMENTAL RESULTS.}

In the series of comparative tests I I samples (indicated by letters in Table I) made by ro different manufacturers were examined. Samples K, L, and II, were of German origin, $\mathrm{L}$ having been purchased in I906. Samples $A$ to $H$ were standard American brands, provided in 50 to I 50 pound drums. 'They were obtained either by purchase on the open market or by purchase or donation from the manufacturer and are believed to represent fairly well the material now used in the refrigeration industries. Several other samples were subjected to a few of the tests. Sample M was an American product purchased in 1907. Sample S was prepared from sample $B$ by several fractional distillations, the first of which was made from metallic sodium.

The results of the comparative tests are given in Table I, opposite the letter indicating the origin of the sample. The column $17323^{\circ}-23-3$ 
headings show the nature of the tests and the manner of expressing the results. In addition to the results in Table I the following data are of interest:

Sample F contained a trace of pyridine and sample $\mathrm{H} 0.02$ per cent. The German samples $I$, and $L / L$ contained 0.015 and 0.005 per cent, respectively. All others contained less than 0.001 per cent.

TABLE 1.-Composition of Commercial Ammonias.

[Note. $-h$ indicates evaporation at room temperature; $l$ indicates evaporation at low temperature.]

\begin{tabular}{|c|c|c|c|c|c|c|c|c|c|c|}
\hline \multirow{4}{*}{$\begin{array}{c}\text { Com- } \\
\text { mercial } \\
\text { sample } \\
\text { desig- } \\
\text { nated. } \\
\\
\end{array}$} & \multicolumn{6}{|c|}{ Noncondensing gas. } & \multirow{4}{*}{$\begin{array}{c}\text { Volatile } \\
\mathrm{C} \text { com- } \\
\text { pounds } \\
(\mathrm{g} \mathrm{CO} 2 \\
\text { per } 100 \mathrm{~g} \\
\left.\mathrm{NH}_{3}\right)^{\circ} \\
0.019\end{array}$} & \multirow{4}{*}{$\begin{array}{c}\begin{array}{c}\text { Residue } \\
\text { on evap- } \\
\text { oration } \\
\text { (per } \\
\text { ceat by } \\
\text { weight). }\end{array} \\
\begin{array}{r}0.012 h \\
.007 l\end{array}\end{array}$} & \multicolumn{2}{|c|}{ Water. } \\
\hline & \multirow{2}{*}{\multicolumn{3}{|c|}{$\begin{array}{l}\text { In the two phases (cc per } \\
100 \mathrm{~g}) \text {. }\end{array}$}} & \multicolumn{3}{|c|}{$\begin{array}{l}\text { Composition (per cent } \\
\text { by volume). }\end{array}$} & & & \multirow{2}{*}{$\begin{array}{c}\text { Method } \\
\text { KOH } \\
\text { (per } \\
\text { cent). }\end{array}$} & \multirow{2}{*}{$\begin{array}{c}\text { Method } \\
\text { CaC }_{2} \\
\text { (per } \\
\text { cent). }\end{array}$} \\
\hline & & & & $\mathbf{N}_{2}$ & $\mathrm{O}_{2}$ & $\mathrm{H}_{2}$ & & & & \\
\hline & $\begin{array}{l}\text { Liquid... } \\
\text { Gas...... }\end{array}$ & $\begin{array}{c}7 \\
\ldots \\
\cdots\end{array}$ & $\cdots \cdots$ & $\begin{array}{l}69.1 \\
86.7\end{array}$ & $\begin{array}{l}30.9 \\
13.3\end{array}$ & $\begin{array}{r}0.0 \\
.0\end{array}$ & & & $\begin{array}{r}0.006 h \\
.001 l\end{array}$ & 0.013 \\
\hline B.... & $\begin{array}{l}\text { Liquid. . } \\
\text { Gas.... }\end{array}$ & 4 & $\ddot{9}$ & $\begin{array}{l}70.8 \\
70.0\end{array}$ & $\begin{array}{l}29.2 \\
30.0\end{array}$ & .0 & .002 & $\begin{array}{l}.009 h \\
.011 l\end{array}$ & $\begin{array}{l}.007 h \\
.008 l\end{array}$ & .042 \\
\hline C..... & $\begin{array}{l}\text { Liquid. . } \\
\text { Gas..... }\end{array}$ & 6 & & $\begin{array}{l}70.3 \\
69.4\end{array}$ & $\begin{array}{l}29.7 \\
30.6\end{array}$ & .0 & .051 & $\begin{array}{l}.008 h \\
.008 l\end{array}$ & $\begin{array}{l}.007 h \\
.005 l\end{array}$ & .030 \\
\hline D.... & $\begin{array}{l}\text { Liquld... } \\
\text { Gas..... }\end{array}$ & 6 & iiz & & $\begin{array}{l}31.6 \\
27.4\end{array}$ & $\begin{array}{l}.0 \\
.0\end{array}$ & .029 & $\begin{array}{l}.014 h \\
.017 l\end{array}$ & $\begin{array}{l}.006 h \\
.004 l\end{array}$ & .030 \\
\hline E... & $\begin{array}{l}\text { Liquid . . } \\
\text { Gas..... }\end{array}$ & 6 & 11 & & $\begin{array}{l}35.0 \\
26.0\end{array}$ & $\begin{array}{l}.0 \\
.0\end{array}$ & .019 & $\begin{array}{l}.011 h \\
.010 l\end{array}$ & $\begin{array}{l}.006 \hbar \\
.006 l\end{array}$ & .030 \\
\hline F... & & 15 & 8032 & $\begin{array}{l}67.0 \\
80.1\end{array}$ & $\begin{array}{l}28.7 \\
19.9\end{array}$ & $\begin{array}{r}4.0 \\
.0\end{array}$ & .061 & $\begin{array}{l}.015 h \\
.022 l\end{array}$ & .......... & $\begin{array}{l}.026 \\
\ldots . .\end{array}$ \\
\hline G... & & 6 & & $\begin{array}{l}70.0 \\
68.0\end{array}$ & $\begin{array}{l}27.0 \\
26.0\end{array}$ & $\begin{array}{l}3.0 \\
6.0\end{array}$ & .032 & $\begin{array}{l}.025 h \\
.100 l\end{array}$ & $\begin{array}{l}.007 h \\
.009 l\end{array}$ & .026 \\
\hline H. . & $\begin{array}{l}\text { Liquid... } \\
\text { Gas.... }\end{array}$ & 6 & & $\begin{array}{l}66.7 \\
66.7\end{array}$ & $\begin{array}{l}33.3 \\
33.3\end{array}$ & $\begin{array}{l}.0 \\
.0\end{array}$ & .902 & $\begin{array}{l}.062 h \\
.134 l\end{array}$ & $\begin{array}{l}.010 h \\
.010 l\end{array}$ & $\begin{array}{l}.027 \\
\ldots . .\end{array}$ \\
\hline $\mathbf{K} . .$. & $\begin{array}{l}\text { Liquid...... } \\
\text { Gas.......... }\end{array}$ & 7 & 19 & $\begin{array}{l}69.0 \\
80.0\end{array}$ & $\begin{array}{l}31.0 \\
20.0\end{array}$ & $\begin{array}{l}\text { trace } \\
\text { trace }\end{array}$ & $\begin{array}{l}.004 \\
. .2 .\end{array}$ & $\begin{array}{l}.276 h \\
.300 l\end{array}$ & $\begin{array}{l}.011 h \\
.032 l\end{array}$ & $\begin{array}{l}.80 \\
\cdots \cdots\end{array}$ \\
\hline L...... & $\begin{array}{l}\text { Liquld..... } \\
\text { Gas........ }\end{array}$ & 9 & $\cdots 5680$ & $\begin{array}{l}77.5 \\
99.4\end{array}$ & $\begin{array}{r}22.5 \\
.6\end{array}$ & $\begin{array}{r}.0 \\
\text { trace }\end{array}$ & $\begin{array}{l}.497 \\
-\cdots+. .\end{array}$ & $\begin{array}{l}.533 h \\
.540 l\end{array}$ & $\begin{array}{l}.041 h \\
.069 l\end{array}$ & $\begin{array}{l}.50 \\
\cdots\end{array}$ \\
\hline LL... & $\begin{array}{l}\text { Liquid...... } \\
\text { Gas........ }\end{array}$ & 15 & $\cdots$ & $\begin{array}{l}79.0 \\
99.3\end{array}$ & $\begin{array}{r}21.0 \\
.7\end{array}$ & .0 & .103 & $\begin{array}{l}.318 h \\
.230 l\end{array}$ & $\begin{array}{l}.053 h \\
.040 l\end{array}$ & $\begin{array}{l}.33 \\
\cdots . . .\end{array}$ \\
\hline & & & & & & & $\begin{array}{l}.014 \\
.011\end{array}$ & $\begin{array}{l}.040 h \\
.051 l\end{array}$ & & $\mid \begin{array}{l}\mid \\
\cdots\end{array}$ \\
\hline & & & & & & & .000 & .000 & & .008 \\
\hline
\end{tabular}

In the samples showing a low residue on evaporation (A to $\mathrm{E}$ ) the residue consisted of a reddish film hardly visible. For the other samples a brownish drop of oily liquid was left, and only for samples K, L, and LL, could the volume of the residues have been measured. The percentage of iron oxide in the residues was greater the smaller the amount of residue in the sample.

Sample F contained 0.005 per cent ammonium acetate, or acetate-forming substance, and sample $\mathrm{L}$ a trace. All others contained less than 0.005 per cent. 


\section{DISCUSSION OF RESULTS.}

The quantity of noncondensing gas found in most samples was surprisingly small. Contrary to the observations of Lowenstein ${ }^{20}$ and Richardson, ${ }^{\circ}$ this gas generally contained a higher percentage of oxygen than does air. Hydrogen was found in four samples, but in no case were hydrocarbon gases or carbon monoxide found. The smallest quantity found in the liquid-namely, $0.04 \mathrm{cc}$ per gram of liquid B-represents about 3 parts in 100,000 by volume. In this laboratory, taking special precautions, ammonia has been prepared whose content of noncondensing gas was less than I part in $I, 000,000$, as measured by the McLeod gage method.

The residues found on evaporation were hardly significant, except in the case of samples G, H, K, L, LI. Sample F, which had a high gas content, gave a small residue. The reverse is true with sample $\mathrm{K}$, showing that there is no necessary relation between gas content and residue.

The results of the combustion tests show a marked difference in the various samples. In practically all the tests no carbon dioxide appeared in the absorber until at least 95 per cent of the liquid had evaporated. Since sample S, prepared in this laboratory, left no residue upon evaporation and gave no carbon dioxide on combustion, it may be safely assumed to be free from all carbonaceous impurities, including hydrocarbons, carbon dioxide, and amines. Upon adding stnall quantities of ethyl amine (boiling point $18^{\circ} \mathrm{C}$.) carbon dioxide was formed from the very start of combustion. As before mentioned, it is probable that with large quantities of carbonaceous impurities the results are low, owing to incomplete combustion.

The results of the water determinations are of interest chiefly in their bearing upon the preparation and testing of small samples prepared in the laboratory. The amounts of water indicated by the potassium hydroxide method are about the same but are low for most of the samples. The determinations by the calcium carbide method indicate that even when little or no water is shown by the evaporation test or by the potassium hydroxide absorption tubes as much as 0.03 to 0.04 per cent may be present. The most nearly anhydrous sample prepared in the laboratory showed 0.004 per cent, as determined by the carbide method. From the tests it seems that pyridine does not ordinarily occur in commercial ammonias except at most in traces. The same may be said of ammonium acetate and with less certainty of acetateforming substances. 
It is recognized that from the results of the various tests one can not with certainty determine the presence or absence, much less the amount, of each of the possible impurities present. They will, however, usually show, on the one hand, the presence of any considerable amount of a given impurity or class of impurities or, on the other hand, its practicable absence, according as the results for the tests concerned are large or negligible. By careful interpretation of all of the results a fairly accurate indication of the specific impurities can be obtained.

\section{CONCLUSIONS.}

(a) Composition of Commercial Ammonias.-In general, the results indicate that about two-thirds of the samples examined are about equally suitable as the starting material for the preparation of pure ammonia to be used in exact chemical or physical work. Even those samples decidedly contaminated could probably be made equal to the better samples by a single distillation, rejecting the last 5 per cent. It is evident that if a closer differentiation of samples is desired physical methods or more sensitive chemical methods of testing must be applied.

(b) METHods of ANalysis. - The results of chemical analysis indicate the adequacy of the simple evaporation test as conducted in many manufacturing plants in detecting samples of poor quality. However, such a test is useless in differentiating the majority of the samples now on the market. The combustion test serves best for small quantities of volatile impurities. This test indicates samples $B$ and $K$ to be more satisfactory than the others in this regard. Methods giving results on water other than those given by the evaporation test are of significance only as regards laboratory preparations.

(c) STANDARDS OF QUALITY.-Even with present methods of analysis it is possible to formulate specifications for liquid ammonia as a chemical reagent, for example, to replace aqua ammonia. In fact, many samples of commercial ammonia now upon the market are more worthy of the designation "chemically pure" than are many of the chemical reagents in use. Until tests under working conditions are conducted it will not be possible to formulate final specifications for ammonia to be used in compression machines. Simple works tests to differentiate samples that can now hardly be distinguished with certainty by elaborate laboratory tests will be still more difficult to devise. 


\section{PREPARATION OF PURE AMMONIA FOR THE DETER- MINATION OF ITS THERMODYNAMICAL PROPERTIES.}

\section{PREVIOUS WORK.}

Many different methods have been used in the purification of ammonia for physical measurements and other purposes. Many investigators did not mention the source or methods of preparation of their material. Many used commercial ammonia direct from the cylinder, while many workers used commercial ammonia as a starting material and put it through a more or less elaborate purification and fractionation process. Blümcke ${ }^{30}$ prepared his ammonia from ammonia water. Joannis ${ }^{31}$ prepared ammonia from pure chemicals and redistilled his product.

Ludeking and Starr ${ }^{32}$ used ammonia which they reported as containing 0.3 per cent of moisture and a slight amount of residue. However, they stated that these impurities could not influence their results within the limits of accuracy desired. Leduc ${ }^{33}$ obtained his ammonia from ammonia water and distilled the product twice, drying it over solid potassium hydroxide. Elleau and Ennis ${ }^{34}$ obtained their ammonia by distilling it directly from a commercial ammonia cylinder. Franklin and Kraus ${ }^{35}$ obtained their ammonia directly from an ammonia cylinder, using precautions to keep solid particles from the cylinder out of the glass line used. Hugot ${ }^{36}$ heated ammonia water, dried the resulting gas with sodium hydroxide, and condensed it in a cooled iron bulb. The liquid was kept in contact with solid sodium. hydroxide and distilled from this container through a drying train into the apparatus to be used. Dieterici and Drewes ${ }^{37}$ condensed the ammonia from a commercial cylinder into another container. The gas phase from this container was used to fill their apparatus. Gibbs ${ }^{38}$ dried commercial ammonia with sodium for a few weeks. The gas phase was then distilled out and condensed in the apparatus used. One of the methods used by Brill ${ }^{39}$ was to employ commercial liquid ammonia, passing it through the train as recommended by Franklin and Kraus. ${ }^{35}$ It was then fractionated three or four times to remove the amines and pyridine bases. As a check on the work of Leduc ${ }^{33}$ on the weight of a normal liter Perman and Davies ${ }^{40}$ used as one of their sources of ammonia the commercial product from an iron cylinder, dried by passing the gas over calcined $\mathrm{CaO}$ and solid sodium hydroxide. Scheffer ${ }^{41}$ distilled the gas from aqua ammonia, condensed it to a liquid with a carbon dioxide bath, and then distilled off a portion of this liquid $17323^{\circ}-23-4$ 
for use in his apparatus. Lange ${ }^{42}$ used technical ammonia direct. Burrell and Robertson ${ }^{43}$ distilled ammonia from aqua ammonia and purified it by repeated distillation at low temperatures.

Ammonia salts were often used as a starting point for pure material by many workers. Frenzel ${ }^{44}$ states that he considers the use of ammonium chloride and lime the simplest method for the production of pure ammonia. He used Merck's ammonium chloride, stating that it was free from pyridine bases. The gas was washed with potassium hydroxide solution and passed through a long train of soda lime, potassium hydroxide sticks, and a potassium oxide-copper oxide mixture for drying, which he describes. No impurities could be found in this ammonia condensed in a bulb. Strock and Blix ${ }^{45}$ and Strock ${ }^{46}$ made up large amounts of the liquid from ammonium chloride and lime. They passed the resulting gas over lime and then over sodium hydroxide. The gas was condensed in glass by cooling the container by means of liquid ammonia. It was then dried by metallic sodium, distilled, and recondensed in the system used.

Brill ${ }^{39}$ states that he used the same method as that used by Frenzel ${ }^{44}$ and fractionated the resulting liquid three or four times to remove the amines and pyridine bases. Berthoud ${ }^{47}$ employed ammonium chloride and sodium hydroxide, using an all-glass train. The ammonia was cooled in a carbon dioxide and ether bath. The resulting liquid was dried with sodium and distilled many times to remove air. Another method was used by Guye and Pintza, ${ }^{48}$ also by Perman and Davies ${ }^{40}$ and Holst, ${ }^{49}$ in making some of their preparations. The method consisted, essentially, in "distilling a portion from an ordinary commercial cylinder in such a way as to avoid the organic impurities." The gas traversed a glass tube heated to redness and containing finely divided $\mathrm{CaO}$. This changed the organic impurities to ammonia and hydrocarbon gases. The ammonia was caught in a hydrochloric acid solution, liberated by heating, and dried in long columns of lime, solid potassium hydroxide, and barium oxide, and then condensed in the usual manner. Guye and Pintza ${ }^{48}$ say that gas made in this way is entirely absorbed, without residue in sulphuric acid. Perman and Davies ${ }^{40}$ state that this method entirely destroys pyridine and proved spectroscopically that none was present. Holst ${ }^{49}$ also tested the gas spectroscopically and found no pyridine present. Holst ${ }^{49}$ collected the gas in a container cooled with liquid air, dried with metallic sodium and fractionated several times, rejecting the first and last fractions. 
Several special methods have been employed in making the pure material. Hartley and Dobbie ${ }^{50}$ found that they could remove pyridine from ammonia by fractional crystallization of the oxalate, and proved it by testing their solution spectroscopically. This was one of the methods of preparation employed by Perman and Davies. ${ }^{40}$ Perman and Davies also made a sample from sodium nitrate by reduction with sodium hydroxide and aluminum. Hartley and Dobbie ${ }^{50}$ prepared ammonia by reducing hydroxylamine hydrochloride with a zinc-copper couple. Travers ${ }^{51}$ mentions the use of magnesium nitride and water. Nitrogen and hydrogen are also formed by this reaction, but Travers states they can be removed by fractionation.

Very little or no attempt was made by the investigators mentioned above to remove the so-called permanent gases from their final pure products. Gibbs ${ }^{38}$ states the presence of these gases would cause errors in certain physical measurements (vapor pressure), but mentions no special precautions taken by him to eliminate them. Several investigators made numerous fractional distillations in vacuum in order to remove these gases, but the soluble gases were probably still present. Keyes and Brownlee ${ }^{52}$ emphasized the fact that the so-called permanent gases were very difficult to remove. They say: "The difficulty of removing with sufficient completeness the dissolved gases does not seem to be particularly emphasized in the descriptions of methods of manipulation heretofore employed in the measurements pertaining to ammonia. The liquid appears to be capable of retaining considerable quantities of permanent gas." Keyes and Brownlee drew a suitable quantity of ammonia furnished by one of the manufacturers into a small steel cylinder containing metailic sodium and then allowed it to stand for some time to insure completeness of removal of water. The ammonia gas was then absorbed by dry solid ammonium nitrate, making it possible to keep the ammonia at room temperature at a moderate pressure. The gases dissolved in the ammonia were assumed to remain in the gas phase above this ammonium nitrate-ammonia solution and to be easily removed by blowing off a small fraction of the gas. It is stated that the dissolved gases were very completely removed by this process. As shown later, however, there is evidence that these gases are reabsorbed by the ammonium nitrate-ammonia solution. The method used by Keyes and Brownlee of testing for the absence of gas by the collapsing of the vapor phase is open to objection 
in principle. This method is described very fully by Young. ${ }^{53}$ Keyes and Felsing ${ }^{54}$ and H. S. Harned ${ }^{55}$ also used this method on other materials and give very good descriptions of the apparatus used, with diagrams. The method consists in trapping a portion of the gas phase under an inverted bell, which is raised for the purpose by means of a magnetic arrangement. If the gas phase collapses completely under the slight hydrostatic head of liquid, it is assumed that there can be very little gas present. Now, if ammonia is capable of retaining the gas so tenaciously, upon its evaporation only that amount of gas would be liberated which was held by the ammonia vaporized. Upon collapsing the gas phase again by means of the inverted bell the gas might again go into solution in the newly condensed ammonia liquid. Thus, no gas residue would be indicated in the inverted bell, and the ammonia would be called gas free. Or, if upon rapid evaporation more gas is liberated than was held by the ammonia evaporated, then the gas and liquid phases are not in equilibrium, and on collapsing the gas phase in the inverted bell the gas might go into solution rapidly, and again the test would indicate that the ammonia was gas free. The above argument is based upon the assumption that the liquid ammonia used has been fractionally distilled in vacuum once or twice to remove any large excess of inert gas.

\section{DESCRIPTION OF APPARATUS.}

(a) Vacuum Fractronal Distillation Apparatus.-The arrangement of apparatus for fractional distillation at pressures less than one atmosphere is shown in Figure 3. This photograph was taken when the apparatus was being used for the purification of methane. The glass bulbs $I, 2$, and 3 each have a capacity of about one-half liter. As shown in Figure 3 , bulbs I and 2 are immersed in Dewar flasks containing liquid air. Condensation of water from the atmosphere in the form of dew and frost gives them a white appearance. The connecting line contains numerous stopcocks in order that these bulbs may be isolated and the material kept at low temperature for indefinite intervals or connected together for the purpose of distillation. They may also be connected separately to the vacuum pump or to the McLeod gage $M$. Each bulb is connected by glass tubing to a small mercury reservoir or trap $t$. These traps serve several purposes: (I) As a manometer to indicate the vapor pressure of the cooled liquid in the bulb, (2) as a convenient means of discarding the first and last fractions of 


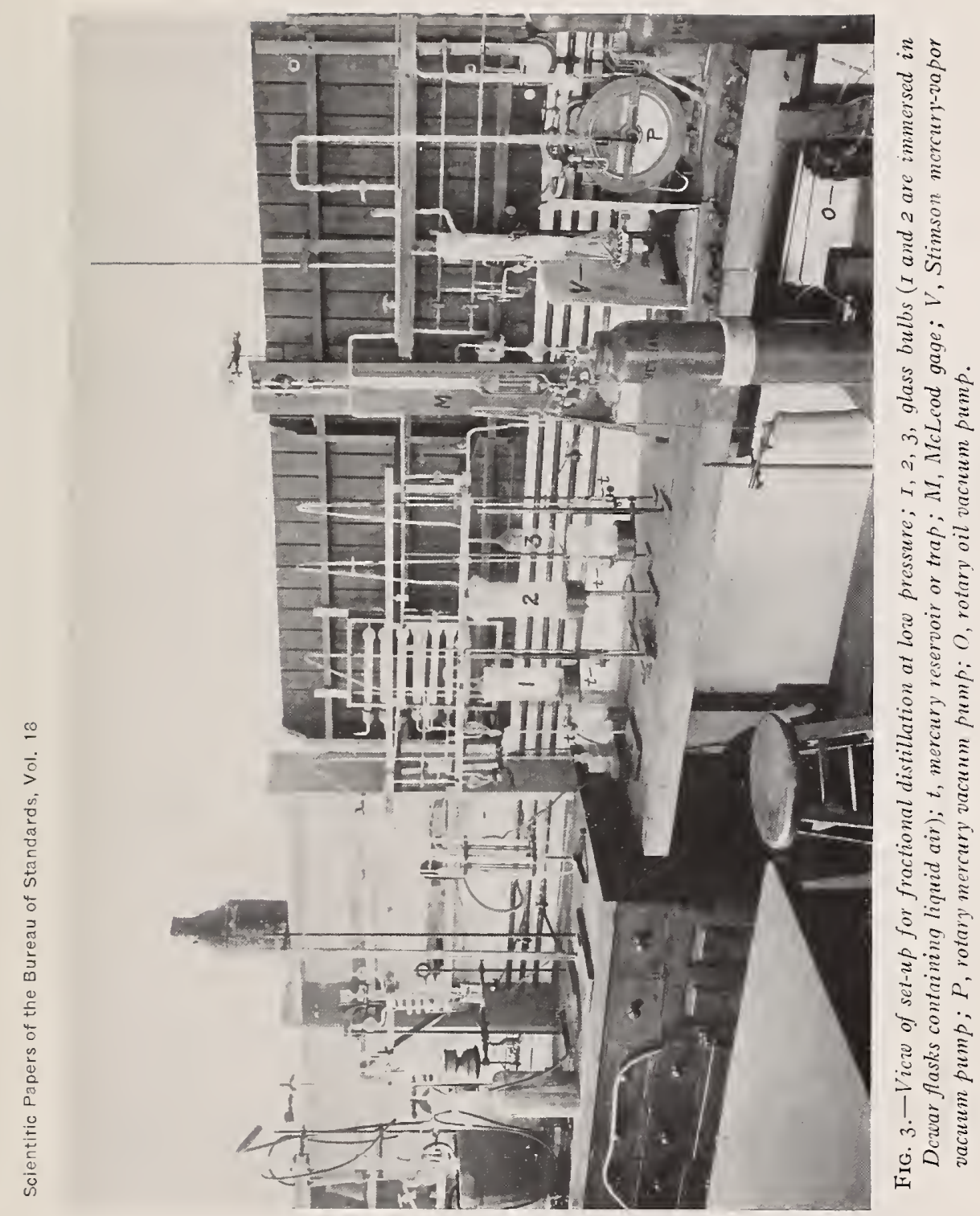


the liquid by allowing the gas to bubble past the mercury in to the atmosphere, and (3) as a safety valve in case of excessive pressure being developed owing to lack of sufficient cooling or to bumping during boiling, which frequently occurs when dealing with highly purified liquids.

In the early part of this work (19I4-I9I6) a Gaede molecular pump and the accompanying forepump were used for the production of high vacua. This pump was fairly satisfactory, but required cleaning frequently. Later a Stimson ${ }^{56}$ two-stage mercuryvapor pump, $V$, of pyrex glass, was installed, which yielded a consistently higher degree of evacuation and was decidedly more convenient. A water aspirator was used to remove any large quan-

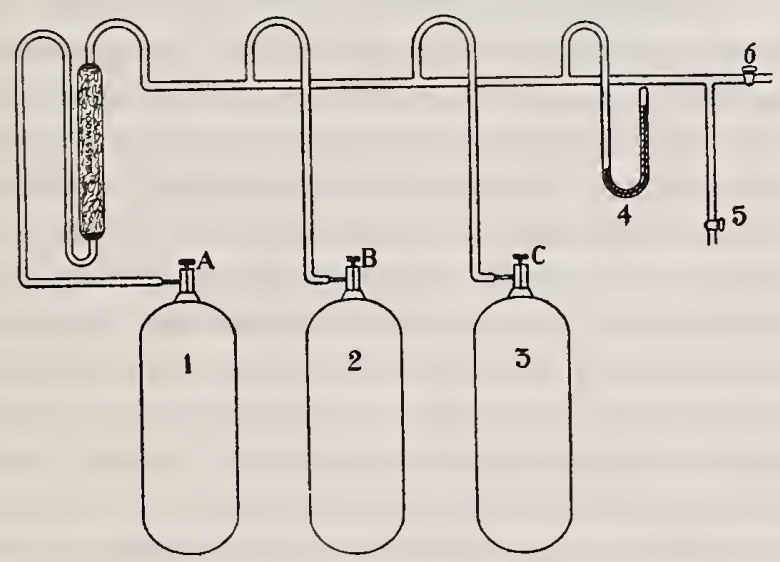

Fig. 4.-Apparatus used for fractional distillation at high pressure; $I, 2,3$, steel bombs, $A, B, C$, steel needle valves; 4 , mercury manometer; 5 , stopcock connection to the atmosphere or water absorber; 6 , stopcock connection to vacuum fractional distillation apparatus and vacuum pump.

tity of ammonia vapor and also for partial evacuation of large volumes. A rotary mercury pump $P$ was sometimes used in series with the Stimson pump. The rotary oil pump $O$ proved more convenient for this purpose, however.

The sensitivity of the McLeod gage $M$ was such that a pressure 0.000 I $\mathrm{mm}$ of mercury could be read with ease. A small flask partially filled with sulphuric acid was connected to the McLeod gage in order to absorb ammonia and to test for the amount of noncondensing gases in various samples, as described later in this paper.

(b) High-Pressure Fractional Distillation Apparatus.The apparatus used for fractional distillations at pressures greater than one atmosphere is shown in Figure 4. It consists chiefly of 
steel containers ( 1,2 , and 3 ) provided with steel needle valves and connected to a glass line by means of glass-to-metal joints (described in a separate paper by McKelvy and Taylor ${ }^{21}$ ). A glass tube filled with glass wool was inserted in the line to prevent the passage of any small solid particles during the first distillation. A capillary $U$ tube 4 , partially filled with mercury and containing air in the closed end, served as a pressure gage during the distillations. The first and last fractions in each distillation were expelled through stopcock 5 either into the atmosphere or into water. The whole apparatus was connected through stopcock 6 to the vacuum distillation apparatus and the vacuum pump.

\section{METHODS OF PREPARATION OF SAMPLES.}

The methods used at this bureau in the preparation of pure samples depended largely upon the amount of material needed and upon the specific physical constant which was to be determined on the sample. The choice of the material used as a source of supply depended also upon the above factors to a large extent.

The method of fractional crystallization of ammonium oxalate used by Hartley and Dobbie and Perman and Davies does not insure the absence of organic bases. The reduction of sodium nitrite by aluminum is also open to objection because of the fact that aluminum contains small amounts of carbon which might form organic impurities during the reduction. Guye in his researches with Pintza showed that ammonia from the decomposition of magnesium nitride contains traces of organic impurities. The ammonia from magnesium nitride also contains some nitrogen and hydrogen, but these gases can be removed by fractional distillation.

It was apparent from the work on commercial ammonias that some of the samples containing only small amounts of impurities were excellent sources of material for further purification-in fact, nearly as good as the ammonia obtained by any of the above methods. It may be noted that samples designated $B$ and $K$, in Table I, contained less organic impurities than any of the other samples. Although $\mathrm{K}$ contained more water than the others ( 0.8 per cent), this could be removed easily by means of metallic sodium. These samples were accordingly chosen as the source of material with which to start the preparation of the pure samples.

Method I.-This is essentially the method used by Guye and Pintza, ${ }^{48}$ Perman and Davies, ${ }^{40}$ and Holst ${ }^{49}$ in their preparation 
of ammonia. Gas from sample $B$, in which no traces of pyridine or ammonium acetate could be detected chemically and which showed a very small amount of carbonaceous material on combustion, was passed through a long tube containing lime heated to red heat. In this process about 20 per cent of the ammonia was decomposed into nitrogen and hydrogen, and the carbon compounds were probably decomposed also. The ammonia was caught in sulphuric acid and the resulting ammonium sulphate crystallized out and heated, above fusion, in a large porcelain evaporating dish. The ammonium sulphate was then dissolved in distilled water, the requisite amount of sodium hydroxide added, and the ammonia distilled from the glass flask containing these materials into an all-glass line, consisting of the following: Tubes containing finely divided potassium hydroxide, tubes filled with freshly ignited lime, and tubes containing barium oxide. After passing through this train the ammonia was condensed in the first bulb of the vacuum fractional distillation apparatus (Fig. 3) by cooling the bulb in a mixture of solid carbon dioxide and gasoline. When nearly filled with liquid, an intervening stopcock was closed and the ammonia was allowed to warm up slowly. The pressure in the bulb rose gradually until it became greater than atmospheric pressure when ammonia vapor bubbled out through the mercury trap. This process was continued until a tenth of the contents had distilled off. Then bulb 2 was cooled and the next eight-tenths distilled into this bulb. The remaining one-tenth was allowed to escape through the trap. These distillations were repeated, the ammonia passing from $\mathrm{I}, 2$, and 3 back to $2, \mathrm{I}$, and so on until six fractional distillations had been completed. By using in the cooling bath either liquid ammonia, carbon dioxide, or liquid air different degrees of vacuum could be maintained in the apparatus during the distiilation. In the last distillation the ammonia was first boiled vigorously and the vapor discarded in an attempt to remove the permanent gases in solution. The middle fraction was then allowed to sublime into the next bulb, which was immersed in liquid air. The ammonia was frozen in small crystals by this process, which proved to be an excellent method of removing the dissolved gases. The remaining gas phase was pumped off by means of the Gaede molecular pump, with an intervening sulphuric acid trap to protect the pump. The solid ammonia was then allowed to warm up until it became liquid, and the gas 
phase was pumped off so rapidly that the ammonia was frozen into small crystals by its own evaporation. After each distillation and operation the ammonia was analyzed for its noncondensing gas content as described later and the final product then distilled into the particular apparatus to be used for physical measurements.

Method 2.-The source of material used in this method was commercial sample B, which was described in a previous part of this paper. No trace of pyridine or ammonium acetate could be detected in this ammonia, by chemical means, and the amount of organic materials found upon combustion proved to be exceedingly small. By means of the combustion test it was observed that practically all of the organic material remained in the last fraction of the first distillation. A few distillations, therefore, should remove the small amount of organic impurities. Accordingly, a sample of $\mathrm{B}$ was distilled from the original drum into a small steel container, which would hold about a kilogram of ammonia. The first portion was distilled off, and the middle portion was distilled into a similar vessel containing metallic sodium in the form of fine wire. The sodium reacted with the water present, forming sodium hydroxide and hydrogen gas. It also reacted with the ammonia, although more slowly, forming sodium amide and hydrogen. Sodium amide, in turn, reacted with water, forming sodium hydroxide and ammonia. In any case, besides obtaining a dry product, an ammonia saturated with hydrogen was obtained. Precautions were therefore taken to remove the noncondensing gases. This was accomplished within certain limits by fractional distillations.

After allowing the ammonia to stand for some time in contact with sodium the first portion was distilled off through a drying train into the air, and the middle portion was distilled into a similar steel container, No. I of the high-pressure fractional distillation apparatus (Fig. 4). The remainder of the high-pressure apparatus was then evacuated with the Stimson pump. The ammonia was allowed to warm to room temperature, and considerable ammonia vapor was absorbed in water. At intervals the gas content was determined by means of a eudiometer and sulphuric acid, as previously described in this paper. After about one-tenth had been blown off container No. 2 was packed in ice and the next eight-tenths condensed therein. The pressure on the glass line during this distillation was about ${ }^{5}$ o lbs./in. ${ }^{2}$. 
The distillation was hastened by immersing No. I in warm water and by discarding the last tenth. Practically the same operation was repeated in distilling from 2 to 3 . These operations were continued until the ammonia had been fractionally distilled eight times. It was next distilled into the vacuum fractional distillation apparatus and there fractionally distilled ten times, using first liquid ammonia as a cooling medium, then carbon dioxide snow and gasoline, and finally liquid air. The sample was sublimed once, using liquid air, and the gas phase was evacuated to a pressure of less than $0.000 \mathrm{rmm}$ of mercury. The solid was then allowed to warm up until it became liquid, and some of the ammonia vapor was allowed to escape through the mercury trap. The sample was then frozen by means of liquid air and again connected with the vacuum pump. After liquefying again it was frozen into small flocculent crystals by its own evaporation, the vapor being pumped off through the vacuum pump and discarded. The content of noncondensing gas was determined after each distillation and manipulation and was found to decrease preceptibly after each operation. The ammonia was finally distilled into the particular glass apparatus to be filled for physical measurements, frozen in liquid air, and the apparatus sealed off with the vacuum pump still in operation. Samples were also taken at the same time for a determination of the water content.

Method 3.-The source of ammonia which was used as a starting material in this preparation is designated $\mathrm{K}$ in the series of analyses of commercial ammonias. This sample was a synthetic ammonia made by the Haber process and was very free from impurities with the exception of water. Since water is very completely removed by metallic sodium, its removal presented no great difficulty. The procedure was exactly the same as in method 2, the ammonia being fractionated eight times in the high pressure distillation apparatus, and ten times in the vacuum distillation apparatus, the first and the last fractions being discarded.

Method 4.-A very much larger sample of ammonia was needed for specific and latent heat determinations than for the determination of the other constants. In the vacuum distillations the greater portion of the ammonia was discarded in the fractionation process, and only a small sample (about $50 \mathrm{cc}$ ) remained for filling the apparatus. The large number of distillations in the other methods were made in order to reduce, as completely as possible, the content of noncondensing gas in the ammonia. Since the presence 
of a small amount of noncondensing gas would have very little effect upon latent and specific heat measurements, it seemed that fewer distillations would suffice. The material was prepared, therefore, using only the high-pressure distillation apparatus.

The commercial ammonia, designated as sample B in Table I, was used as the source of material. Some of this ammonia was transferred by distillation into one of the small steel containers. The first portion was discarded by blowing off through the valve, and about nine-tenths of the remainder was distilled into a similar vessel containing sodium wire to remove the water. After allowing this container to stand for some time with occasional shaking the first portion, containing considerable hydrogen, was blown off. The gas phase was tested from time to time by the eudiometer method. When the content of noncondensing gas became small, the remainder, with the exception of the last $50 \mathrm{cc}$, was distilled into the high-pressure distillation apparatus. Eight fractional distillations were made in this apparatus, the first and last fractions being discarded in each case. It was finally distilled into a steel container for use in the calorimetric determinations.

Method 5.-The procedure followed in this method was identical with that of method 4 , the only difference being in the source of material. The source of this material was the sample of synthetic ammonia prepared by the Haber process, designated $\mathrm{K}$ in Table $\mathrm{I}$.

\section{TESTS FOR NONCONDENSING GASES.}

(a) Application OF McLEOd Gage.-The apparatus used in testing the gas content in ammonia consisted of a McLeod gage and a small bulb containing concentrated sulphuric acid which had been previously heated (see Fig. 3). This bulb was made of pyrex glass and connected to the soda glass line by several steps of especially prepared glasses, varying in composition. After the bulb was partially filled, put in place, and evacuated the sulphuric acid was again heated to expel any water and gas. The bulb could be connected to or disconnected from the McLeod gage by rotating the bulb. This rotation gave an additional advantage in that a fresh surface of acid was always exposed.

The test for gas content was performed in the following manner: The entire McLeod gage, including the sulphuric acid bulb, was evacuated by means of the Stimson vacuum pump until the pressure was less than $0.0001 \mathrm{~mm}$ of mercury. The sulphuric acid bulb was then turned off and ammonia admitted into the McLeod 
gage to atmospheric pressure. The McLeod gage was then closed off from the rest of the line, the sulphuric acid bulb turned on, and the ammonia absorbed in the acid. The residual pressure was then read on the McLeod gage at intervals of a few minutes. About 30 minutes were necessary to complete the entire operation.

The above data, together with the estimated volume of the McLeod gage and connections and the estimated volume above the acid in the sulphuric acid bulb, furnished sufficient data to calculate the proportionate amount of noncondensing gases in the ammonia.

Let $p=$ pressure in the system, exclusive of acid bulb, when filled with $\mathrm{NH}_{3}$.

$p_{1}=$ partial pressure of noncondensing gases in $\mathrm{NH}_{3}$.

$p^{\prime}=$ pressure in entire system, including the acid bulb, after exhaustion and before admitting $\mathrm{NH}_{3}$.

$p^{\prime \prime}=$ pressure in entire system after absorption of $\mathrm{NH}_{3}$.

$p_{2}=p^{\prime \prime}-p^{\prime}=$ pressure due to noncondensing gases in $\mathrm{NH}_{3}$.

$V_{1}=$ volume of system, excluding acid bulb.

$V_{2}=$ volume of system, including acid bulb.

Since the gas under consideration remains approximately at room temperature during this operation, Boyle's law may be applied, namely, that $p_{1} V_{1}=p_{2} V_{2}$. Thus, the partial pressure of the noncondensing gas in the ammonia is

$$
p_{1}=\frac{p_{2} V}{V_{1}}=\frac{\left(p^{\prime \prime}-p^{\prime}\right) V_{2}}{V_{1}}
$$

Since the initial quantities of noncondensing gas and ammonia are proportional to their respective partial pressures, the ratio, by volume, of noncondensing gas to ammonia is given by

$$
\frac{p_{1}}{p}=\frac{\left(p^{\prime \prime}-p^{\prime}\right) V_{2}}{p V_{1}}
$$

The following values apply to the system as actually used: $V_{1}=200 \mathrm{~cm}^{3}, V_{2}=250 \mathrm{~cm}^{3}, p=760 \mathrm{~mm}$ of mercury, and

$$
\frac{p_{1}}{p}=0.00165\left(p^{\prime \prime}-p^{\prime}\right) \text {. }
$$

By using great care in the evacuation of the system and in the removal of the noncondensing gases as described in method 2 the best test gave $p^{\prime}=0.00005 \mathrm{~mm}, p^{\prime \prime}=0.00060 \mathrm{~mm}$, and $\frac{p^{\prime}}{p}=0.00165(0.00060-0.00005)=9 \times 10^{-7}$, or slightly less than one part in a million of noncondensing gas. 
A question of importance in connection with this method of testing is the solubility of the noncondensing gases in concentrated sulphuric acid. Since the acid had been heated and well evacuated previous to a series of tests, possibly some of the noncondensing gas was absorbed during the test, this making the apparent results too low. That the effect of this absorption at such low pressure was serious is doubtful for two reasons: (I) Because the temperature of the surface of the acid during the test was high owing to the absorption of ammonia, and in some cases the surface consisted of a sheet of ammonium sulphate, and (2) because repeated determinations on the same sample with varying concentration of sulphuric acid in the acid bulb yielded very consistent results. In any case the results show

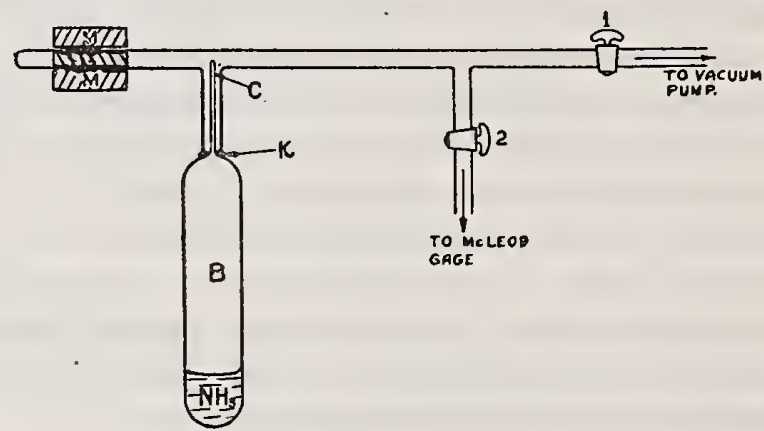

FIG. 5.-Sketch of arrangement used in opening glass apparatus containing ammonia into a vacuum for gas content determination; $M$, permanent magnet; $H$, magnetic hammer (soft iron encased in a sealed glass tube); $C$, scratch in capillary tube; $K$, Kotinsky cement; $B$, glass bulb; $I, 2$, stopcocks.

the relative amounts of noncondensing gas in the different samples made by different methods and are probably correct in order of magnitude.

(b) Liberation of Gases in SEaling OFF Glass Apparatus.During the process of sealing off glass apparatus after filling with the purified sample and freezing the ammonia with liquid air the vacuum pump was always connected to the line and apparatus. Even with this precaution considerable gas might have been liberated in heating the glass and have remained in the apparatus. In order to test this point, several pieces of apparatus were opened to the McLeod gage by means of a magnetic hammer, and the gas content measured after the physical measurements on the ammonia had been completed. The magnetic hammer was somewhat similar to that described by Peck, ${ }^{57}$ except that no steel spring 
was necessary in this case. The scheme of the apparatus is shown diagramatically in Figure 5. The bulb $B$, or any other piece of apparatus containing the liquid ammonia, was cooled in liquid air, scratched with a glass knife at $C$, and sealed to the glass line at $K$ with Khotinsky cement. The hammer $H$ consisted of a piece of soft iron encased in a sealed glass case and was operated by means of the magnet $M$. The system was pumped down below 0.000 I $\mathrm{mm}$ of mercury with the Stimson pump, stopcock I closed, and the tip broken by impact with the magnetic hammer. The bulb was then allowed to warm up, and sufficient ammonia was admitted to the McLeod gage through stopcock 2 to fill it at atmospheric pressure. The gas determination was carried out as described in the preceding section.

(c) Ammonia from Ammonium Nitrate Solution.--Measurements were also made on the gas content of ammonia after having been absorbed in dry ammonium nitrate. This was the method recommended by Keyes and Brownlee ${ }^{52}$ to very completely remove dissolved gases. A glass container of approximately the shape described by Keyes and Brownlee, ${ }^{52}$ having a volume of $600 \mathrm{cc}$ and containing about $400 \mathrm{cc}$ of dry ammonium nitrate, was used for this purpose. This apparatus was connected to the glass line by a spiral of glass tubing which gave a very flexible connection and permitted vigorous shaking of the container. The whole apparatus was heated and well evacuated. Ammonia was passed into the ammonium nitrate until all the solid disappeared and only liquid was present. After allowing a small amount of ammonia to escape from the glass container some of the remaining ammonia was tested for noncondensing gas. The first volume was too large to be read on the McLeod gage. About one-eighth of the liquid was then allowed to evaporate and another test made. The gas content was 6 parts per 100,000. After one-sixth of the liquid had evaporated the gas content was 3 parts per 100,000. After one-fourth of the liquid had evaporated the gas content was 2 parts per 100,000 . When only a small amount of liquid remained in the bulb and most of the ammonium nitrate had separated out as a solid, the gas content became $I$ part in 100,000. After repeated trials it was concluded that the above result was the best attainable by this method. As a comparison the following are some of the results obtained on the ammonia purified by fractional distillation. Repeated determinations on various samples of ammonia have shown that the content of noncondensing gas in 
the product obtained after completing the fractional distillations at high pressure is about I part in I0,000. After distilling five times in the vacuum fractional distillation apparatus the gas content became I part in 100,000. By removing considerable ammonia vapor with a vacuum pump and allowing the liquid to become frozen by its own evaporation the gas content became I part in $\mathrm{I}, 000,000$.

\section{RESULTS AND DISCUSSION.}

During the course of this investigation I 5 purified samples were prepared by 5 somewhat different methods. The results of the tests on the various samples, and also the character of the physical measurements made upon each sample, are shown in Table 2

TABLE 2.-Data on Purified Samples of Ammonia.

\begin{tabular}{|c|c|c|c|c|c|c|c|}
\hline \multirow[b]{2}{*}{$\begin{array}{l}\text { Date of prepara- } \\
\text { tlon. }\end{array}$} & \multirow[b]{2}{*}{$\begin{array}{c}\text { Desig- } \\
\text { nation } \\
\text { of sam- } \\
\text { ples. }\end{array}$} & \multirow[b]{2}{*}{ Method. } & \multirow[b]{2}{*}{$\begin{array}{l}\text { Volume } \\
\text { of fin- } \\
\text { ished } \\
\text { product. }\end{array}$} & \multirow[b]{2}{*}{$\begin{array}{c}\text { Water } \\
\text { content } \\
\text { by } \\
\text { weight } \\
\text { less } \\
\text { than- }\end{array}$} & \multicolumn{2}{|c|}{ Gas content. } & \multirow[b]{2}{*}{$\begin{array}{l}\text { Physical measurements made } \\
\text { upon samples. }\end{array}$} \\
\hline & & & & & $\begin{array}{c}\text { In vapor } \\
\text { phase at } \\
25^{\circ} \text { C. } \\
\text { and } 760 \\
\text { mon } \\
\text { (parts } \\
\text { per mil- } \\
\text { lion). }\end{array}$ & $\begin{array}{c}\text { On } \\
\text { opening } \\
\text { sealed } \\
\text { appara- } \\
\text { tus } \\
\text { (parts } \\
\text { per mil- } \\
\text { lion). }\end{array}$ & \\
\hline $\begin{array}{l}\text { November, } 1915 \ldots \\
\text { March, } 1916 . \ldots . . \\
\quad \text { Do............. }\end{array}$ & $\stackrel{\mathbf{F}}{\mathbf{G}}$ & $\begin{array}{l}1 \\
1 \\
4\end{array}$ & $\begin{array}{r}\mathrm{cm}^{3} . \\
50 \\
50 \\
700\end{array}$ & $\begin{array}{c}\text { Per } \\
\text { cent. } \\
0.003 \\
.003 \\
.012\end{array}$ & $\begin{array}{l}70 \\
10 \\
90\end{array}$ & 10 & \multirow{7}{*}{$\begin{array}{l}\text { Specific volume, liquid and vapor. } \\
\text { Do. } \\
\text { Specific heat and specific volume } \\
\text { of liquid. } \\
\text { Latent heat of vaporization. } \\
\text { Specific heat of liquid. } \\
\text { Latent heat of pressure variation. } \\
\text { Specific volume, liquid and vapor. } \\
\text { Do. } \\
\text { Specific volume, vapor; vapor } \\
\text { pressure (manometers } A \text { and } \\
\text { special). } \\
\text { Specific volume, liguld, and vapor } \\
\text { refractive index. } \\
\text { Vapor pressure (manometers } \mathbf{B}_{1} \text {, } \\
\mathbf{B}_{3,}, \mathbf{C}_{1}, \mathbf{C}_{2} \text { ). } \\
\text { Vapor pressure (manometers } \mathbf{B}_{2} \\
\text { and } \mathbf{B}_{4} \text { ). } \\
\text { Triple point. } \\
\text { Specific volume, liquid, and } \\
\text { superbeated vapor. } \\
\text { Specific heat of superheated } \\
\text { vapor. }\end{array}$} \\
\hline $\begin{array}{l}\text { May, } 1916 \ldots \ldots \ldots \\
\text { July, } 1916 \ldots \ldots \ldots \\
\text { January, } 1917 \ldots \ldots \\
\text { February, } 1917 \ldots \ldots \\
\text { May, } 1917 \ldots \ldots \ldots \\
\text { February, } 1918 \ldots \ldots\end{array}$ & $\begin{array}{l}\mathbf{B} \\
\mathbf{C} \\
\mathbf{D} \\
\mathbf{H} \\
\mathbf{I} \\
\mathbf{K}\end{array}$ & $\begin{array}{l}5 \\
5 \\
4 \\
1 \\
3 \\
2\end{array}$ & $\begin{array}{r}700 \\
700 \\
700 \\
50 \\
50 \\
50\end{array}$ & $\begin{array}{l}.009 \\
.010 \\
.010 \\
.003 \\
.003 \\
.003\end{array}$ & $\begin{array}{c}100 \\
80 \\
70 \\
37 \\
10 \\
0.9\end{array}$ & 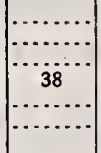 & \\
\hline June, $1918 \ldots .$. & $\mathbf{L}$ & 2 & 50 & .003 & 1.0 & 3.6 & \\
\hline February, 1919.. & $\mathbf{M}$ & 3 & 50 & .003 & 1.5 & & \\
\hline May, $1919 \ldots \ldots \ldots$ & $\mathbf{N}$ & 3 & 50 & .003 & 1.0 & & \\
\hline $\begin{array}{l}\text { July, } 1919 \ldots \ldots \ldots \\
\text { April, } 1920 \ldots \ldots \ldots\end{array}$ & $\stackrel{\circ}{P}$ & $\begin{array}{l}3 \\
3\end{array}$ & $\begin{array}{r}50 \\
650\end{array}$ & $\begin{array}{l}.003 \\
.003\end{array}$ & $\begin{array}{l}1.0 \\
2.0\end{array}$ & & \\
\hline$D_{0} \ldots . .$. & $\mathbf{Q}$ & 5 & 2,500 & .010 & 100 & & \\
\hline
\end{tabular}

The limitations in the method of testing for water were such that the results are not reliable to better than 0.003 per cent. The content of noncondensing gas was reduced by sublimation and also by allowing the ammonia to be frozen by its own evaporation. Repeating this process several times, the gas content could be reduced to about one-tenth of its former value. Upon 
opening some of the containers to the McLeod gage with a magnetic hammer and making gas determinations it was shown definitely that no injurious amounts of gas were introduced into the apparatus by sealing off by fusion.

The commercial ammonia used as a source of material in the purification of these samples was tested chemically for pyridine (lower limit of test sensitivity $0.00 \mathrm{r}$ per cent) and a negative result obtained. The original material was also tested for organic impurities and only very slight amounts were found (less than I part in 50,000, calculated as carbon dioxide from the combustion test). The test for organic impurities in the final products gave negative results, as did the spectroscopic test for pyridine.

\section{MISCELLANEOUS PHYSICAL CONSTANTS OF AMMONIA.}

\section{DENSITY OF SOLID.}

A search through various physical tables indicated that the density of solid ammonia had not been determined. It seened desirable, therefore, to make a determination of the density of the solid with the moderate precision attainable with the facilities at hand.

For this purpose a glass picnometer, which had been previously calibrated and employed in the determinations of the specific volume of liquid ammonia, ${ }^{5}$ was attached to a metal needle valve by means of a glass-to-metal joint ${ }^{21}$ and partially filled with a purified sample of ammonia. This picnometer resembled somewhat a thermometer in that it consisted of a bulb (about $5 \mathrm{cc}$ in capacity) at the bottom, a small expansion bulb near the top, and a long capillary upon which an arbitrary scale had been etched. The lower bulb was immersed in a mixture of solid carbon dioxide and gasoline whose temperature was about $I^{\circ}$ lower than the freezing temperature of ammonia. The ammonia remained as an undercooled liquid, however, and in order to start crystallization the tip of the bulb was dipped in liquid air for a few seconds. The bulb was then replaced in the carbon dioxide bath and the pressure above the latter reduced by evacuation until a temperature of about $-85^{\circ} \mathrm{C}$. was obtained. After all the ammonia in the bulb had solidified it was allowed to remain in the carbon dioxide bath (at atmospheric pressure) for a considerable time, and the volume of the solid and also the small volume of the liquid in the capillary were then observed. Another determination of the density of the solid was made by slowly freezing the ammonia in liquid air. 
The picnometer was filled a second time and the above procedure was repeated. The two sets of determinations differed in the amount of liquid ammonia above the solid. In the first determinations the temperature of the surface of the liquid was approximately $0^{\circ} \mathrm{C}$. and in the second about $25^{\circ} \mathrm{C}$. The pressures in the

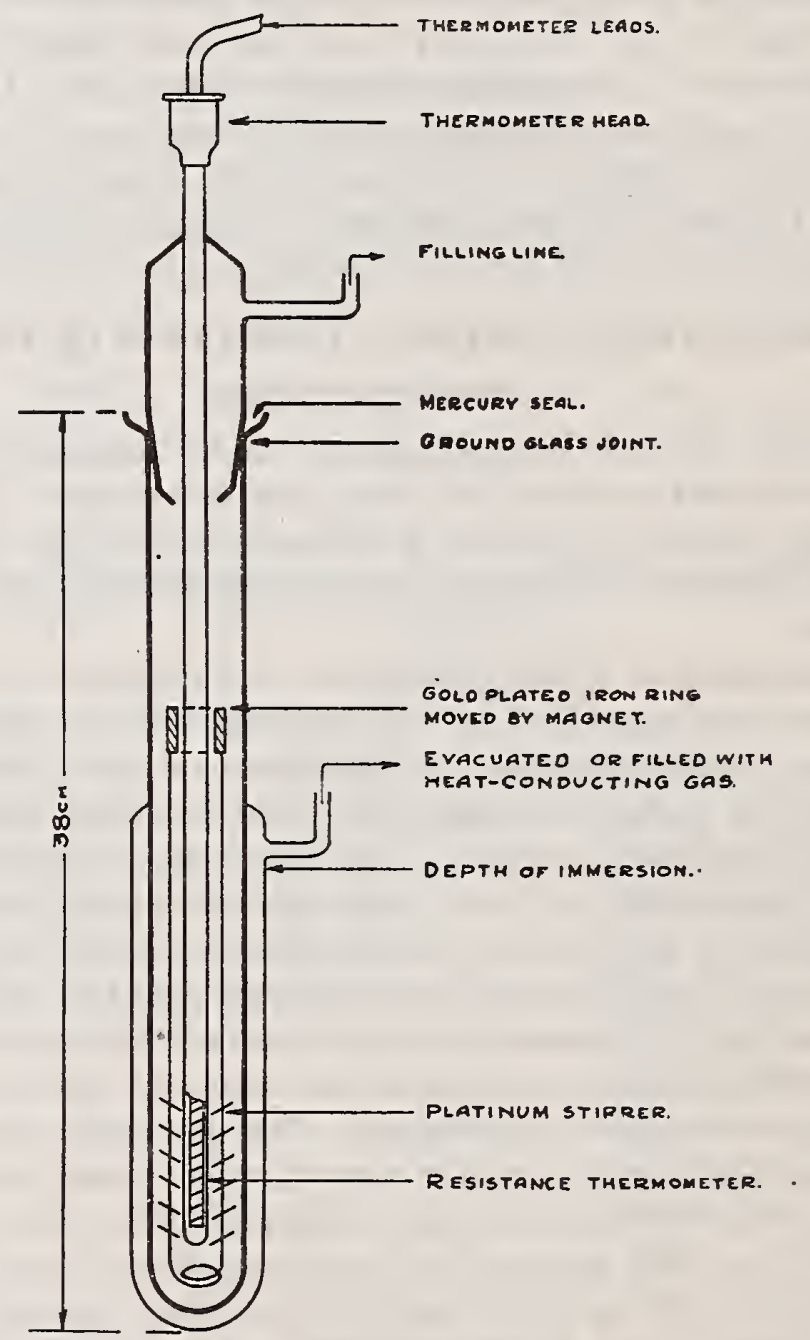

FIG. 6.-Freezing-point apparatus.

picnometer in the two cases were therefore about 4 and Io atmospheres, respectively. The agreement of the determinations was about I part in 500 . The density of solid ammonia was found to be $0.817 \mathrm{~g} / \mathrm{cm}^{3}$ at $-79^{\circ} \mathrm{C}$. and $0.836 \mathrm{~g} / \mathrm{cm}^{3}$ at $-185^{\circ} \mathrm{C}$., and the mean coefficient of linear expansion $7 \times 10^{-5}$ per $^{\circ} \mathrm{C}$. 


\section{TEMPERATURE AT THE TRIPLE POINT AND ELEVATION OF FREEZ- ING POINT WITH PRESSURE:}

A special apparatus shown in Figure 6 was constructed of pyrex glass for the determination of the freezing temperature of various pure liquids. This apparatus was partially immersed in a bath which consisted of a Dewar flask containing petroleum ether. The bath was provided with a motor-driven stirrer and a thinwalled copper tube into which liquid air was siphoned in small quantities. $^{d}$

After evacuation a portion of a purified sample of ammonia was distilled into the apparatus until the surface of the liquid ammonia reached the level of the petroleum ether in the bath. Ammonia vapor was then pumped off, and a portion of the liquid ammonia was frozen into small crystals by its own evaporation. The mixture of solid and liquid ammonia was automatically stirred by means of the platinum stirrer (shown in Fig. 6) and the movement of an external magnet. The temperature of the mixture with the three phases-solid, liquid, and vapor-present was then observed by means of a platinum resistance thermometer, which had been previously calibrated in ice, steam, and sulphur vapor. The mean of four determinations of the temperature at the triple point (see Table 3 ) is $-77.70^{\circ} \mathrm{C}$.

TABLE 3.-Observed Freezing Temperature of Ammonia.

\begin{tabular}{|c|c|c|}
\hline Date. & Volume of contents in cublc centimeters. & $\begin{array}{l}\text { Observed } \\
\text { tempera- } \\
\text { ture. }\end{array}$ \\
\hline \multirow[t]{4}{*}{ 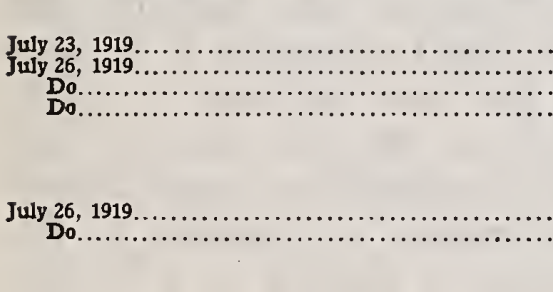 } & 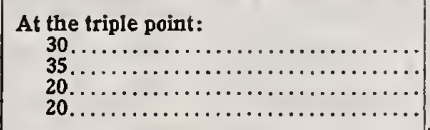 & $\begin{array}{l}-77.704 \\
-77.709 \\
-77.684 \\
-77.689\end{array}$ \\
\hline & Mean........ & -77.696 \\
\hline & 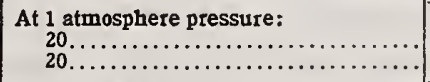 & $\begin{array}{l}-77.699 \\
-77.703\end{array}$ \\
\hline & Mean...$\ldots \ldots \ldots \ldots \ldots \ldots \ldots$ & -77.701 \\
\hline
\end{tabular}

Air at atmospheric pressure was admitted to the apparatus through a calcium chloride drying tube and the temperature again observed. As shown in Table 3, this operation was followed

\footnotetext{
d While attempting further determinations of the freezing point of ammonia with this apparatus in November, r9r9, an explosive mixture of the combined vapors from liquid air and petroleum ether was accidentally ignited, presumably by a spark from the commutator of the motor or by static discharge and resulted in the death of Mr. McKelvy, the senior author of this paper. Attention is here drawn to the danger connected with the cambined use of inflammable liquids and liquid air for low temperature baths. There is danger in the use of any inflammable liquid in a Dewar flask, which may fail at any moment, unless suitable precautions are taken to protect the observer.
} 
by a slight lowering of the indicated temperature. Theoretically, the freezing point of a liquid which contracts upon solidification should rise with increased pressure.

It may be of interest to calculate for ammonia the magnitude of the elevation of the freezing point with pressure. This calculation is usually made by employing Clapeyron's equation in the following form:

$$
\delta \theta=\frac{\theta\left(v_{2}-v_{1}\right) \delta p}{L}
$$

At the temperature of the triple point, $\theta=195^{\circ}$ (abs), the specific volume of the liquid $v_{2}=1.363 \mathrm{~cm}^{3} / \mathrm{g}$ (taken from previous paper ${ }^{5}$ ), the specific volume of the solid $v_{1}=1.224$ $\mathrm{cm}^{3} / \mathrm{g}$ (the reciprocal of the above value found for the density), and the latent heat of fusion $L=108 \mathrm{cal} / \mathrm{g}$ (quoted from Massol) ${ }^{58}$. Thus, for a change in pressure of one atmosphere $\delta p=10^{\circ}$ dynes $/ \mathrm{cm}^{2}$, approximately, the elevation of the freezing point is

$$
\delta \theta=\frac{195(\mathrm{I} .363-\mathrm{I} .224) 10^{6}}{108 \times 4.18 \times 10^{7}}=0.006^{\circ} \mathrm{C} \text {. per atmos. }
$$

That a small decrease instead of an increase in the temperature of the freezing point was observed may have been due to a small amount of moisture which was not removed from the air by the calcium chloride, or possibly to air being dissolved in the ammonia or simply to observational error.

\section{VAPOR PRESSURE AT THE TRIPLE POINT.}

In conjunction with the determination of the temperature at the triple point, two determinations of the vapor pressure were made by connecting the freezing point apparatus to a small mercury manometer. Readings were taken with aid of a cathetometer and corrections applied for the depression of the mercury menisci. The mean of two determinations, which differed by $0.2 \mathrm{~mm}$, gave, for the vapor pressure of ammonia at the triple point $\left(-77.70^{\circ} \mathrm{C}\right.$. $), 45.2 \mathrm{~mm}$ of mercury at $0^{\circ} \mathrm{C}$. and standard gravity $(\mathrm{g}=980.665)$.

The temperature scale used in these measurements is the scale defined by the resistance thermometer of pure platinum, calibrated in ice, steam, and sulphur vapor $\left(444.6^{\circ} \mathrm{C}\right.$. taken as the normal boiling point of sulphur). Using the Callendar equation

$$
t=\frac{R_{t}-\mathrm{R}_{0}}{R_{100}-R_{0}} \mathrm{IOO}+\delta\left(\frac{t}{\mathrm{IOO}}-\mathrm{I}\right) \frac{t}{\mathrm{IOO}}
$$


as an interpolation equation the temperature scale so defined represents the centigrade thermodynamic scale in the interval -50 to $+45^{\circ} \mathrm{C}$. to the accuracy with which that scale is at present known. By direct comparison of several platinum resistance thermometers with a constant volume hydrogen thermometer at temperature below $-50^{\circ} \mathrm{C}$., Henning ${ }^{59}$ found the corrections necessary to reduce to the gas scale the temperatures determined with the above equation. From Henning's results, a correction of $+0.08^{\circ}$ has been applied to the measurement at $-77.70^{\circ} \mathrm{C}$.

\section{SUMMARY.}

Methods for the testing of commercial ammonia have been described and applied to eight standard American brands and three brands of German origin. The results of these analyses indicate that most commercial ammonias contain less than o. I per cent of impurities. Previous methods used for the preparation of pure samples have been briefly reviewed and discussed. Apparatus used for fractional distillations at pressures greater and also less than atmospheric pressure are described.

Emphasis has been placed upon the removal of noncondensing gases, and methods of removal and testing have been described in detail, together with a method for opening sealed glass containers and testing the contents for noncondensing gases.

Five methods for the preparation of samples have been described in detail and the physical measurements made upon each sample indicated. The different preparations have been tabulated, together with the analyses and uses.

Ammonia has been prepared which contained, as far as any known test indicated, no organic impurities, less than I part in $\mathrm{I}, 000,000$, by volume, of noncondensing gases, and less than 0.003 per cent, by weight, of water.

The following physical properties of pure ammonia were determined: The density of the solid, $0.817 \mathrm{~g} / \mathrm{cm}^{3}$ at $-79^{\circ} \mathrm{C}$. and $0.836 \mathrm{~g} / \mathrm{cm}^{3}$ at $-\mathrm{I} 85^{\circ} \mathrm{C}$.; the freezing point, $-77.70^{\circ} \mathrm{C}$., and the vapor pressure at that temperature, $45.2 \mathrm{~mm}$ of mercury.

\section{REFERENCES CITED IN PAPER.}

I. N. S. Osborne and M. S. Van Dusen, B. S. Bulletin, 14, p. 397, I917 (or B. S. Sci. Papers, No. 313); J. Am. Soc. Refrig. Eng., 4, p. I34, I9I7; J. Am. Chem. Soc., 40, p. I, I9I8.

2. N. S. Osborne and M. S. Van Dusen, B. S. Bulletin, 14, p. 433, I9I7 (or B. S. Sci. Papers, No. 314); J. Am. Soc. Refrig. Eng., 4, p. I67, I917. 
3. N. S. Osborne and M. S. Van Dusen, B. S. Bulletin, 14, p. 439, I917 (or B. S. Sci. Papers, No. 315); J. Am. Soc. Refrig. Eng., 4, p. 172, I917; J. Am. Chem. Soc., 40, p. I4, IgI8.

4. C. S. Cragoe, C. H. Meyers, and C. S. Taylor, B. S. Sci. Papers, 16, p. I, Ig20 (or B. S. Sci. Papers, No. 369); J. Am. Soc. Refrig. Eng., 6, p. 307, I920; J. Am. Chem. Soc., 42, p. 206, 1919.

5. C. S. Cragoe and D. R. Harper, 3d, B. S. Sci. Papers, 17, p. 287, I92I (or B. S. Sci. Papers, No. 420); J. Am. Soc. Refrig. Eng., 7, p. II 3, I920.

6. E. C. McKelvy and C. S. Taylor, J. Am. Soc. Refrig. Eng., 3, p. 30, I9I7.

7. H. von Strombeck, J. Franklin Inst., 134, p. 58-64, I64-I66, I892.

8. A. Lange and W. Heffter, Chemische Industrie, 21, p. 2-7, 1898; abst. J. Soc. Chemical Industry, 17, p. I83-184, I898; Chemisches Zentralblatt, 1, p. 4I6, I8g8.

9. W. D. Richardson, J. Ind. Eng. Chem., 2, p. 97-99, I9ro.

Io. A. W. Browne and A. E. Houlehan, J. Am. Chem. Soc., 35, footnote, p. 65I, Igז3.

II. A. Lange and J. Hertz, Zs. angewandte Chemie, p. 224-228; I897; abst. Chemisches Zentralblatt, 1, p. 943, I897.

I2. K. Urban, Chemiker-Zeitung, 21, p. 720, I897; abst. Chemisches Zentralblatt, 2, p. 807,1897 .

I3. F. W. Frerichs, J. Ind. Eng. Chem., 1, p. 362-369, Ig09.

I4. H. Dannenbaum, Publications of National Ammonia Co.

I5. A. Lange, Wochenschrift Brauerei, No. 34, 1897; abst. Zs. f. komprimierte und flüssige Gase, 1, p. I48-I49, I897; also Zs. f. d. gesamte Kälte-Industrie, I897.

I6. H. Bunte and P. Eitner, J. f. Gasbeleuchtung, 40, p. 174-I75, I897; abst. Chemisches Zentralblatt, 1, p. 770, I897.

77. R. Iucion and D. De Paepe, Bulletin Société Chimique de Belgique, 20, p. 347-35I, Ig06; abst. Chemisches Zentralblatt, 1, p. 1807, I907.

18. Richter, Deutsches Reichs Gebrauchs-Muster (German patent) 122449, Klasse 12; 1899 .

I9. Roller, Deutsches Reichs Gebrauchs-Muster (German patent) 75580, Klasse 42, 1897.

20. H. Sallwasser, jr., Thesis, Washington University, IgI2; (rendered available by courtesy of the National Ammonia Co.).

21. E. C. McKelvy and C. S. Taylor, J. Am. Chem. Soc., 42, p. 1364; 1920.

22. R. S. McBride and E. R. Weaver, B. S. Tech. Papers, No. 20; 19I3.

23. E. R. Weaver and J. D. Edwards, J. Ind. Eng. Chem., 7, p. 620-62I; I9I5.

24. E. R. Weaver and J. D. Edwards, J. Ind. Eng. Chem., 7, p. 534; I9I5.

25. E. R. Weaver, J. Am. Chem. Soc., 38, p. 352-36r, I916, (or B. S. Bulletin, 13, p. 27, I $916-17$ ).

26. A. Lange, Wochenschrift Brauerei, 15, p. 93; 1898 .

27. J. C. Sparks, Trans. Am. Soc. Refrig. Eng., 3, p. I44-I46; I907.

28. F. W. Frerichs, Trans. Am. Inst. Chem. Eng., 6, p. 214-216; I9I3.

29. A. Lowenstein, J. Am. Soc. Brewing Technology, 6, No. 5, March I9I6; abst. J. Am. Soc. Refrig. Eng., 3, p. 25 ; 1916.

3o. A. Blümcke, Wied. Ann., 34, p. 18; 1888.

3т. A. Joannis, C. R., 115, p. 822 ; I892.

32. C. Irudeking and J. E. Starr, Phil. Mag., 35, p. 393, I893; Am. J. Sci., 145, p. 200,1893 .

33. A. Leduc, C. R. 125, p. $57 \mathrm{I} ; \mathrm{I} 897$.

34. I. A. Elleau and W. D. Ennis, J. Franklin Inst., 145, p. I89, 28o; 1898.

35. E. C. Franklin and C. A. Kraus, Am. Chem. J., 20, p. 839, I898; Am. Chem. J., 23, p. 277, I900.

36. C. Hugot, Ann. d. Chimie et d. Physique, (7), 21, p. II; I900.

37. C. Dieterici and H. Drewes, Zs. f. d. gesamte Kälte-Industrie, 11, p. 2 I, 47 ; 1904. 
38. H. D. Gibbs, J. Am. Chem. Soc., 27, p. 85 ; $x 905$.

39. O. Brill, Ann. d. Phys. (4), 21, p. I70; 1906.

40. E. P. Perman and J. H. Davies, Proc. Roy. Soc. (London) A, 78, p. 28; 1907.

4I. F. E. C. Scheffer, Zs. Phys. Chem., 71, p. 69r; rgro.

42. A. Lange, Chemische Industrie, 21, p. I9I,I898; Zs. f. d. gesamte Kälte-Industrie, 5, p. $39 ; 1898$.

43. G. A. Burrell and I. W. Robertson, J. Am. Chem. Soc., 37, p. 2482; I9r5.

44. C. Frenzel, Zs. f. Electrochemie, 6, p. $485 ; 1900$.

45. A. Strock and M. Blix, Berichte d. Deutschen Chem. Gesellschaft, 34, p. 3039; rgor.

46. A. Strock, Berichte d. Deutschen Chem. Gesellschaft, 39, p. 1967; 1906.

47. A. Berthoud, Helvetica Chimica Acta, 1, p, 84; $x 918$.

48. P. A. Guye and A. Pintza, C. R., 141, p. 5I, r905; J. d. Chimie Physique, 5, p. 225,1907 .

49. G. Holst, Les propriétés thermiques de l'ammoniaque et du chlorure de méthyle. Thesis, Zurich Federal Polytechnic School, Leiden, I913; 3d Int. Cong. Refrig., Sept., xgr 3 ; Bull. Assoc. Int. Froid, 6, p. 48, 19x 5.

50. W. N. Hartley and J. J. Dobbie, J. Chem. Soc. (London), 77, p. 318; 1900.

5I. M. W. Travers, Experimental Study of Gases, McMillan \& Co. Igor.

52. F. G. Keyes and R. B. Brownlee, J. Am. Chem. Soc., 40, p. 25 ; 1918.

53. F. B. Young, Phil. Mag. (6), 20, p. 797; xgro.

54. F. G. Keyes and W. A. Felsing, J. Am. Chem. Soc., 41, p. 604; I9I9.

55. H. S. Harned, J. Am. Chem. Soc., 42, p. 372; $x_{920 .}$

56. H. F. Stimson, J. Wash. Acad. Sci., 7, p. 477; x9r7.

57. E. B. Peck, J. Am. Chem. Soc., 40, p. 335; Igr8.

58. Massol, C. R., 134, p. 655; 1902.

59. F. Henning, Ann. d. Phys., (4), 40, p. 653; х9r3.

6o. C. Schmitz, Eis und Kälte-Industrie, 5, p. I5; 1903.

Washington, September I8, I 922. 




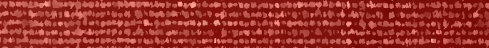

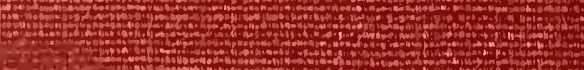

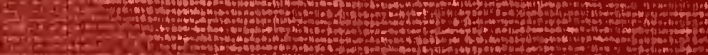

$\frac{x+2}{2 x}$

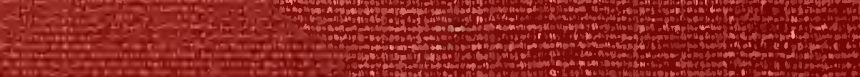

